\title{
15. HIGH SOUTHERN LATITUDE MAGNETOSTRATIGRAPHY AND ROCK MAGNETIC PROPERTIES OF SEDIMENTS FROM SITES 747, 749, AND 751 ${ }^{1}$
}

\author{
Franz Heider, ${ }^{2,3}$ Beate Leitner, ${ }^{3}$ and Hiroo Inokuchi ${ }^{4}$
}

\begin{abstract}
The magnetostratigraphy of Sites 747,749 , and 751 of Leg 120 that was established by shipboard measurements was extended and confirmed. Five hundred and eighty sediment cubes were stepwise demagnetized with alternating fields to determine their characteristic remanence. We obtained a rather complete magnetostratigraphy from the Oligocene to the Pliocene for the nannofossil oozes of Site 747. Alternating-field demagnetization experiments on laboratory-induced magnetization, hysteresis measurements, and low-temperature experiments showed that the magnetic carriers are single-domain and small pseudo-single-domain (titano)magnetite particles. A fraction of these $\mathrm{Fe}-\mathrm{Ti}$ oxides seems to reside as microlites in the vitric volcanic ash particles that were enriched in the magnetic separates. The natural remanent magnetizations seem to be of detrital origin with small Fe-Ti oxide grains in the volcanic glass particles as carriers of the stable paleomagnetic signal.
\end{abstract}

\section{INTRODUCTION}

The objective of Ocean Drilling Program (ODP) Leg 120 was to investigate the origin and tectonic history of the Kerguelen Plateau in the South Indian Ocean. The magnetostratigraphy of the cored sediments was determined so that we could accurately date the biostratigraphic events. One aim of our study was to contribute to a combined magnetobiostratigraphy in high southern latitudes (Harwood et al., this volume; Berggren et al., this volume). In this paper we present results obtained from the single sediment samples of Sites 747, 749, and 751. The results from Sites 748 and 750 are described elsewhere (Inokuchi et al., this volume). The cores described here were recovered with the advanced hydraulic piston corer (APC) and the extended core barrel (XCB). The best paleomagnetic results were obtained on the generally well-preserved APC cores, as was previously found by Sager (1988).

During Leg 120 a preliminary magnetostratigraphy was determined with the cryogenic magnetometer on the JOIDES Resolution using split 1.5 -m-long sections of the core. The shipboard magnetometer worked extremely well, compared with previous legs, and a record of declination, inclination, and intensity of magnetization was obtained from all undisturbed cores. Nevertheless, the maximum alternating field (AF) that was available for demagnetization of the cores during the cruise was $9 \mathrm{mT}$. We had previously noticed that the magnetostratigraphic record became more similar to the standard polarity reversal sequence following removal of a normal overprint with the available 9-mT AF treatment (Schlich, Wise, et al., 1989). The question remained whether the 9-mT AF demagnetization was sufficient to isolate the characteristic inclinations, especially since some inclinations measured on board the ship were much shallower than the $72^{\circ}$ expected for the high-latitude location.

\footnotetext{
${ }^{1}$ Wise, S. W., Jr., Schlich, R., 1992. Proc. ODP, Sci. Results, 120: College Station, TX (Ocean Drilling Program).

${ }^{2}$ Geophysics Laboratory, Department of Physics, University of Toronto, Toronto, Ontario, M5S 1A7, Canada.

${ }^{3}$ Institut für Allgemeine und Angewandte Geophysik, Ludwig-MaximiliansUniversität, Theresienstrasse 41,8 München 2, Federal Republic of Germany.

${ }^{4}$ Department of Earth Sciences, Faculty of Science, Kobe University, Kobe 657, Japan.
}

The aim of the land-based measurements was to test the validity of the preliminary magnetostratigraphy from the ship and to fill in gaps that still existed in our record. Rock magnetic measurements were done on the sediments to characterize the magnetic remanence carriers. Biogenic singledomain (SD) magnetite has been found as the carrier of magnetization in detritus-poor pelagic sediments (Petersen et al., 1986). The sediments used for the magnetostratigraphy were mainly of pelagic origin and consisted of nannofossil, foraminiferal, and diatom ooze. Mainly carbonate-rich sediments were encountered because all sites were in $2100-\mathrm{m}$ water depth well above the calcium carbonate compensation depth (CCD). Rock magnetic investigations were conducted to determine the magnetic domain state of the samples.

In addition to biogenic SD magnetite, we investigated the role of vitric volcanic ash particles as carriers of stable magnetization. We follow the nomenclature for detrital remanent magnetizations (DRM) suggested in the review on sedimentary magnetism by Verosub (1977). A depositional DRM is a magnetization acquired by magnetic grains in the Earth's field while settling in water and on first contact with the sediment. A postdepositional DRM is formed after deposition when the magnetic particles are surrounded by sediment.

\section{METHODS}

Samples were taken with standard ODP cubes $\left(7 \mathrm{~cm}^{3}\right)$ during the cruise. On average we obtained two samples per $1.5-\mathrm{m}$ section of the core, when the sediment was not disturbed. Cubes were pressed into the sampling half of the core with the arrow on the plastic cube pointing in the upcore direction. The harder sediments were precut with a sharp stainless steel spatula before sampling with a plastic cube.

The paleomagnetic measurements were carried out in the Paleomagnetism Laboratory of the Universität München with a two-axis cryogenic magnetometer. Magnetizations as weak as $3 \leq 10^{-5} \mathrm{~A} / \mathrm{m}$ could be measured on the single samples with this magnetometer. All samples were stepwise AF-demagnetized in three directions. Approximately 580 samples from Holes 747A-747C, 749B, and 751A were AF-demagnetized in at least five steps up to $60 \mathrm{mT}$ in order to isolate their characteristic remanence components.

The declinations of the single samples have no meaning because the cores were not oriented with respect to azimuth. 
A
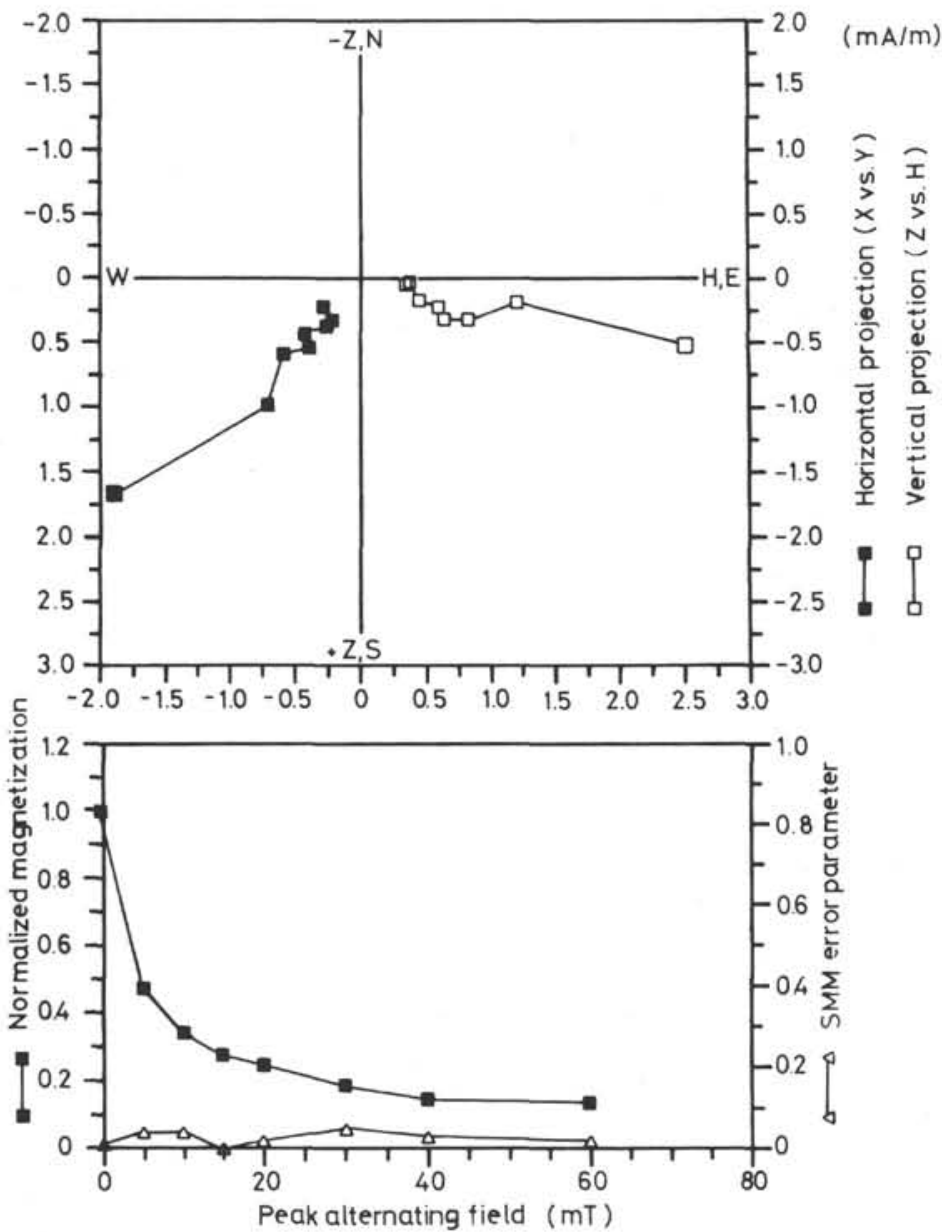

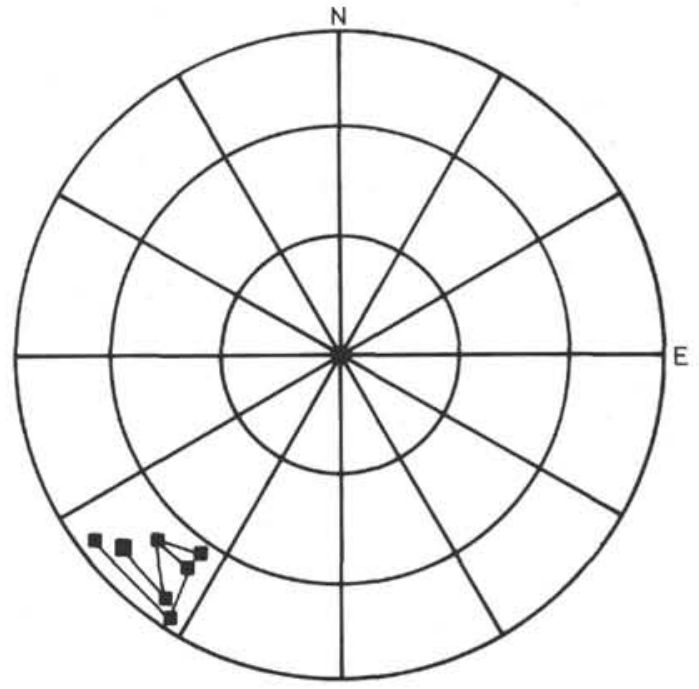

- Positive inclination

口 Negative inclination

Figure 1. Vector projections (Zijderveld diagrams), stereographic projections, and intensity decay curves during alternating field demagnetization of natural remanent magnetizations. A. Sample 120-747A-7H-3, 112-114 cm, with an initial soft magnetization and shallow characteristic inclination of $22^{\circ}$. B. Sample $120-751-15 \mathrm{H}-5,120-122 \mathrm{~cm}$, with high coercivity values (MDF $=48 \mathrm{mT}$ ) and a characteristic inclination of $38^{\circ}$.

The characteristic inclination of each sample was determined from straight line segments of the AF-demagnetization data in vector projections (Zijderveld plot) (Fig. 1). Results from samples with unstable magnetization (e.g., switching polarity of inclination) or from low intensity of magnetization $(<3 \leq$ $10^{-5} \mathrm{~A} / \mathrm{m}$ ) were discarded. Only samples with more or less stable inclinations were considered suitable for the magnetostratigraphic purposes. Median destructive fields (MDF) were determined from decay curves of magnetization intensity vs. peak alternating field (Fig. 1). No MDF could be determined for a few samples when the magnetization had not decreased to $50 \%$ at $60-\mathrm{mT}$ AF treatment or when an anhysteretic remanent magnetization (ARM) was induced at high alternating fields.

It was generally found that parts of the core that were too weakly magnetized to be measured with the pass-through cryogenic magnetometer on board the JOIDES Resolution were also too weakly magnetized for measurements on land. The higher sensitivity of the cryogenic magnetometer on land was offset by the smaller sample volumes $\left(7 \mathrm{~cm}^{3}\right)$ compared with the larger split halves of the cores measured on the ship.

Eleven sediment samples were selected from different lithotypes and sub-bottom depths from Sites 747 and 751 for detailed rock magnetic studies. Differences in hardness of the AF demagnetization curves of the natural remanent magnetization (NRM) were used as a selection criterion. These sediment cubes were given anhysteretic remanent magnetization (ARM) and isothermal remanent magnetization (IRM), which were measured with a Digico spinner magnetometer. Hysteresis parameters were measured with a very sensitive magnetic translation balance in a high field solenoid $\left(H_{\max }=\right.$ $300 \mathrm{mT}$ ) that was recently developed by von Dobeneck. Following the magnetic measurements on the 11 samples, magnetic separates were obtained with a liquid extraction technique (von Dobeneck et al., 1987) from the sediment cubes that contained sufficient magnetic material. The magnetic extracts were investigated by X-ray diffraction (XRD), energy dispersive X-ray analysis, and scanning and transmission electron microscopy (SEM and TEM) as well as being used for Curie temperature determinations.

\section{MAGNETOSTRATIGRAPHY}

Site 747

Site 747 lies between the northern and southern Kerguelen Plateau at about $55^{\circ}$ southern latitude. For a description of the lithologic and biostratigraphic units the reader is referred to the corresponding articles in Schlich, Wise, et al. (1989) and in this volume. The magnetostratigraphic record determined from the shipboard inclination data (stars) and the characteristic inclinations of single sample cubes (circles) is shown in Figure 2. Negative inclinations (I) correspond to normal 

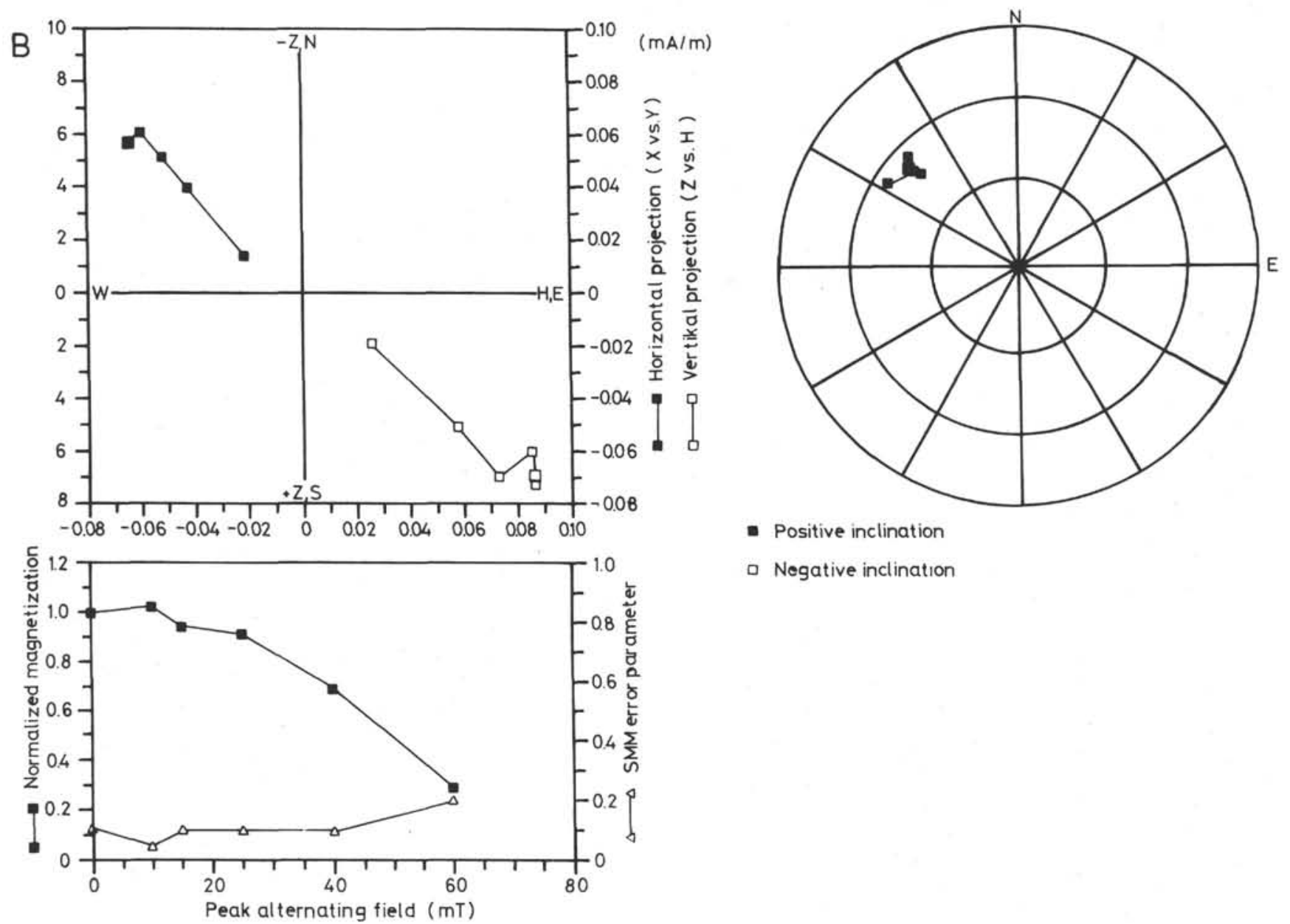

- Positive inclination

Figure 1 (continued).

polarity of the earth's magnetic field, and positive inclinations to reversed polarity. It is evident from the inclination data in Figure 2 that the inclinations from separate samples confirm in most cases the results obtained during Leg 120. An interpretation of the inclination record in terms of normal and reversed polarity is shown by black and white colors, respectively, in the column between the inclination and the MDF (Fig. 2). Magnetic polarity chrons could be identified by correlating our results to a standard magnetic time scale (Berggren et al., 1985) and by considering biostratigraphic results (see Harwood et al., this volume; Berggren et al., this volume).

In addition to the magnetostratigraphy presented in the Proceedings of the Ocean Drilling Program, Initial Reports, Volume 120 (Schlich, Wise, et al., 1989), we obtained the following new results. The top of Subchron C2A (Gauss) is observed at Holes 747 A and 747B at 21.5 and $19.6 \mathrm{~m}$ below seafloor (mbsf), respectively. The top of the Cochiti (Chron C3) in Hole 747B is pinned down by single sample results at 26.8 mbsf. The hiatus that occurs at 34.3 mbsf in Hole $747 \mathrm{~A}$ seems to cut the lower part of Chron C3 (the normal polarity of the Gilbert). Therefore, the hiatus can be inferred to start at about 4.5 m.y. It is evident from the position of Subchron C4A that the sub-bottom depth at Hole $747 \mathrm{~A}$ can differ by as much as $4 \mathrm{~m}$ from the depth found for Hole 747B.

The top of Chron C5 around $48 \mathrm{mbsf}$ at Hole $747 \mathrm{~A}$ is not known, but the top of the short normal period (C4AN3) above Chron 5 is found at 45.5 mbsf. The bottom of Chron C 5 , which was previously thought to occur at $52.5 \mathrm{mbsf}$ in Hole $747 \mathrm{~A}$, is now uncertain. The results from the single specimens contradict the measurements from the ship between 52.5 and 55 mbsf, and it is possible that Chron C5 continues down to at least 55 mbsf in Hole 747A. In Hole 747B we confirmed a transition from normal to reversed polarity at $50 \mathrm{mbsf}$ that may represent the bottom of Chron $\mathrm{C} 5$.

The preliminary magnetostratigraphy (Schlich, Wise, et al., 1989) had to be reinterpreted between 62 and 77 mbsf based on stable isotope data of Wright and Miller (this volume). Based on a maximum in $\delta^{18} \mathrm{O}$ at $70 \mathrm{mbsf}$ at Site 747 the reversed interval there is interpreted as C5ABR and the subsequent normal intervals are reinterpreted accordingly (Wright and Miller, this volume). The normal polarity interval between 70 and $72 \mathrm{mbsf}$ is now C5AC and the next normal is C5AD. The two normal intervals of Chrons C5A and C5AA are linked together. The two normal intervals of Chron C5B shifted slightly upward compared with the shipboard results.

The beginning of Chron C5D is found at $93.5 \mathrm{mbsf}$ in Hole $747 \mathrm{~A}$. At 120.6 mbsf we identified the second normal polarity interval of Chron C6AA, which was not clearly recognizable from the shipboard data. The reversal sequence between 123 and 161 mbsf was easily identified as Subchrons C6B through Chron C10. Coring with the APC stopped at 151.5 mbsf where the lithology changed from nannofossil ooze (Subunit IIA) to nannofossil chalk (Subunit IIB). Additional data place the bottom of Chron $\mathrm{C} 10$ at 161.5 mbsf. There is a major hiatus below 170 mbsf. The top of a normal subchron, which may be 
Hole 747 A

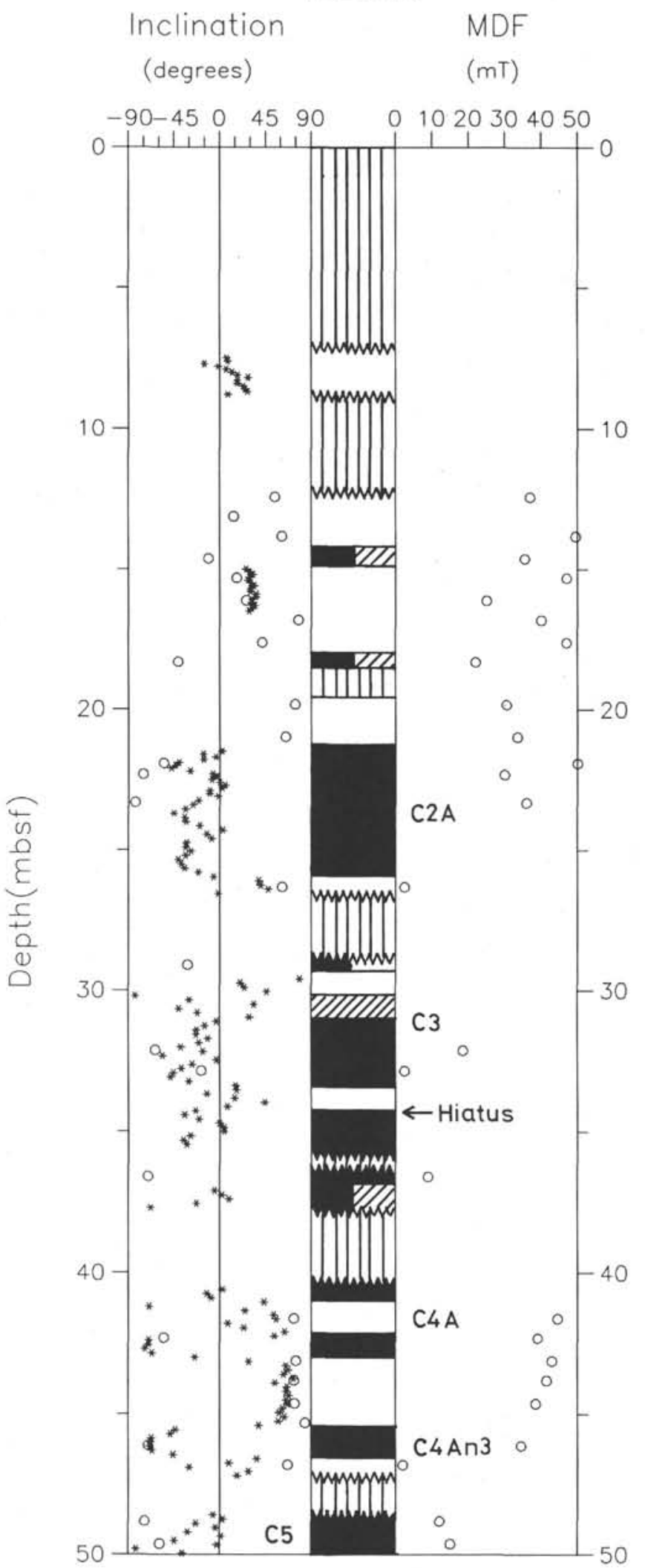

Hele $747 B$

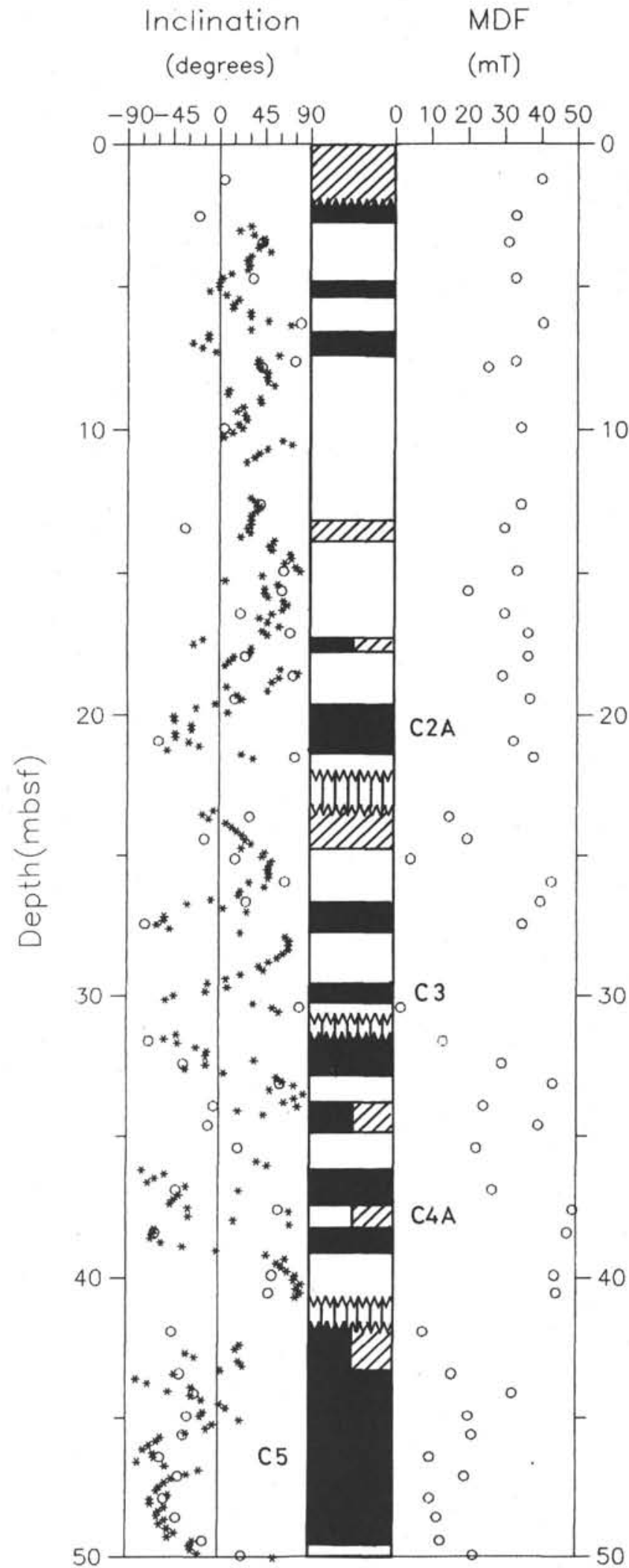

Figure 2. Depth plots of inclinations from shipboard measurements (stars) and single samples (circles) for Holes $747 \mathrm{~A}(0-250 \mathrm{mbs}$ ) and $747 \mathrm{~B}$ (0-50 mbsf). Interpretation of inclination record in terms of magnetic polarity reversals: black for normal polarity, white for reversed polarity, diagonal stripes for uninterpretable data, and vertical stripes for lack of data. Median destructive fields (MDFs) of natural remanent magnetizations (NRMs) were obtained from the single-sediment cubes. 
Hole 747 A

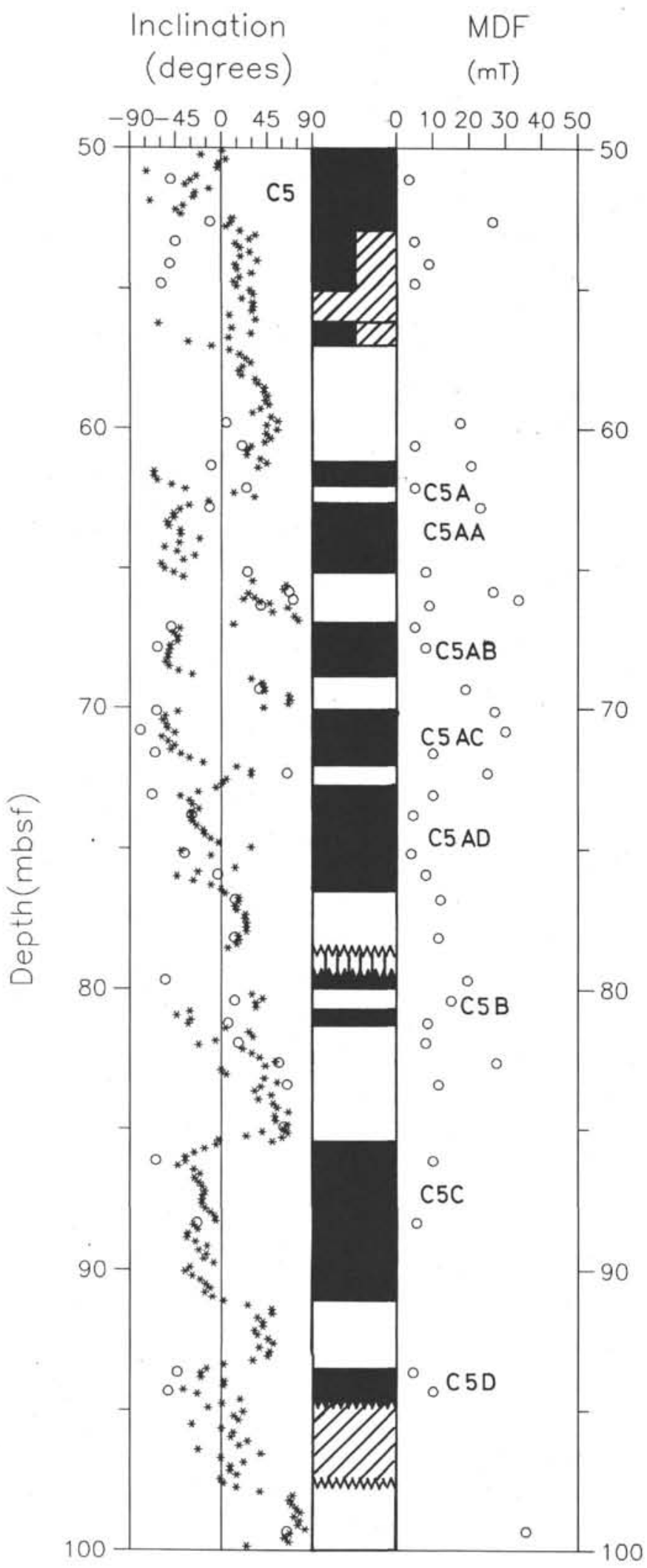

Hole 747A

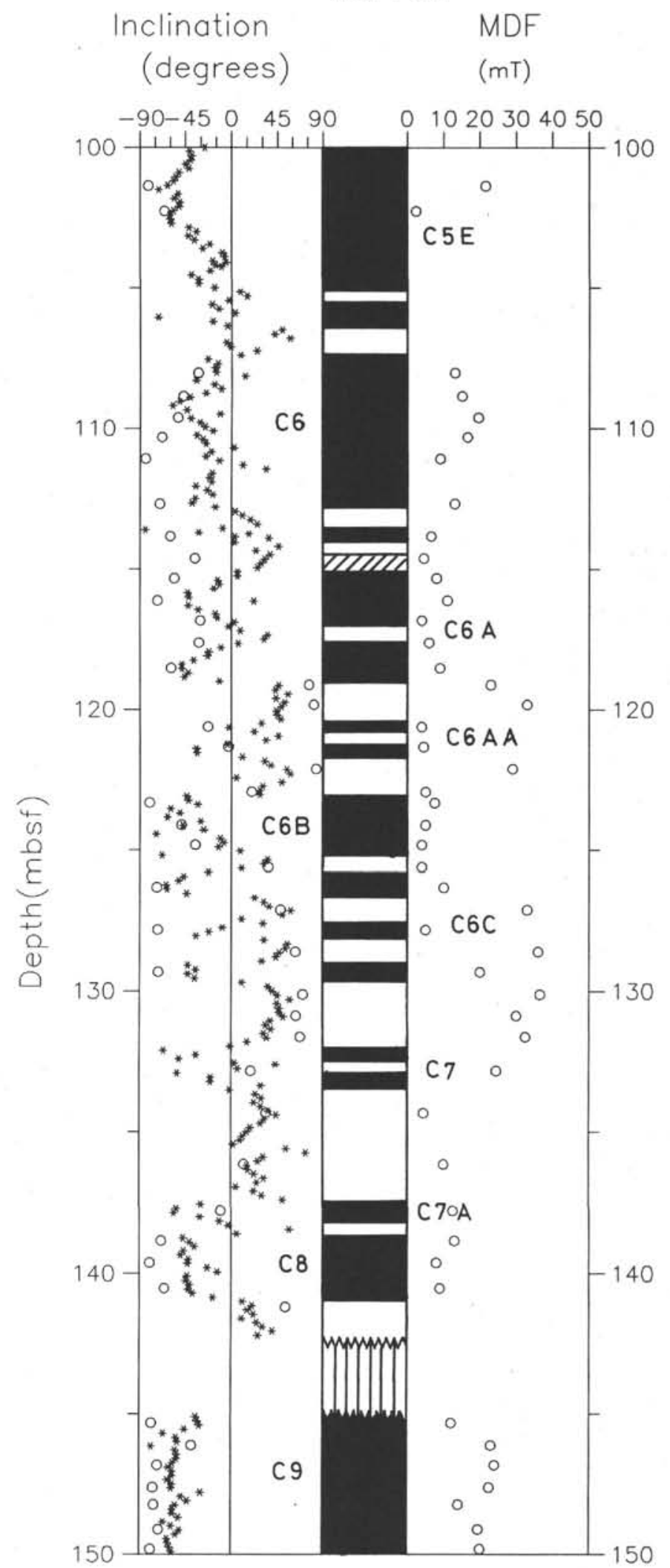

Figure 2 (continued). 
Hole $747 \mathrm{~A}$

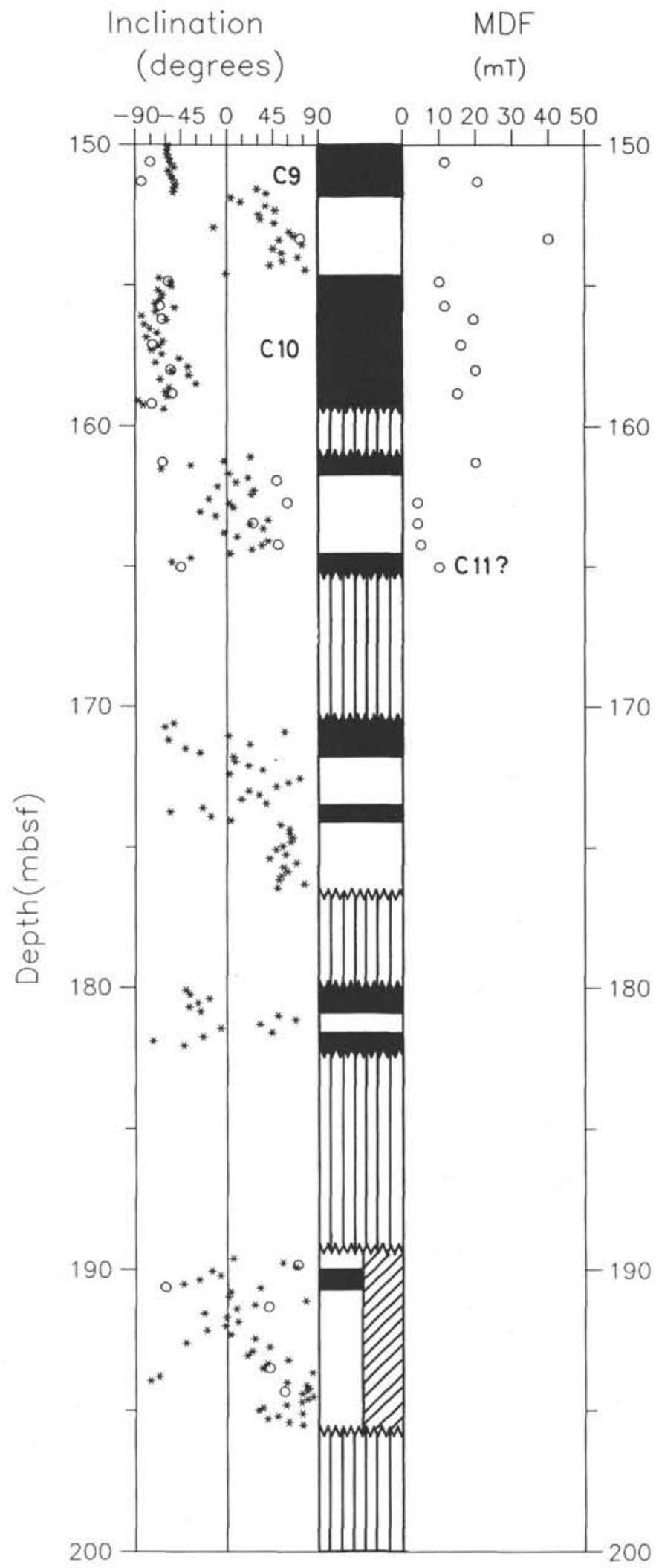

Hole 747A
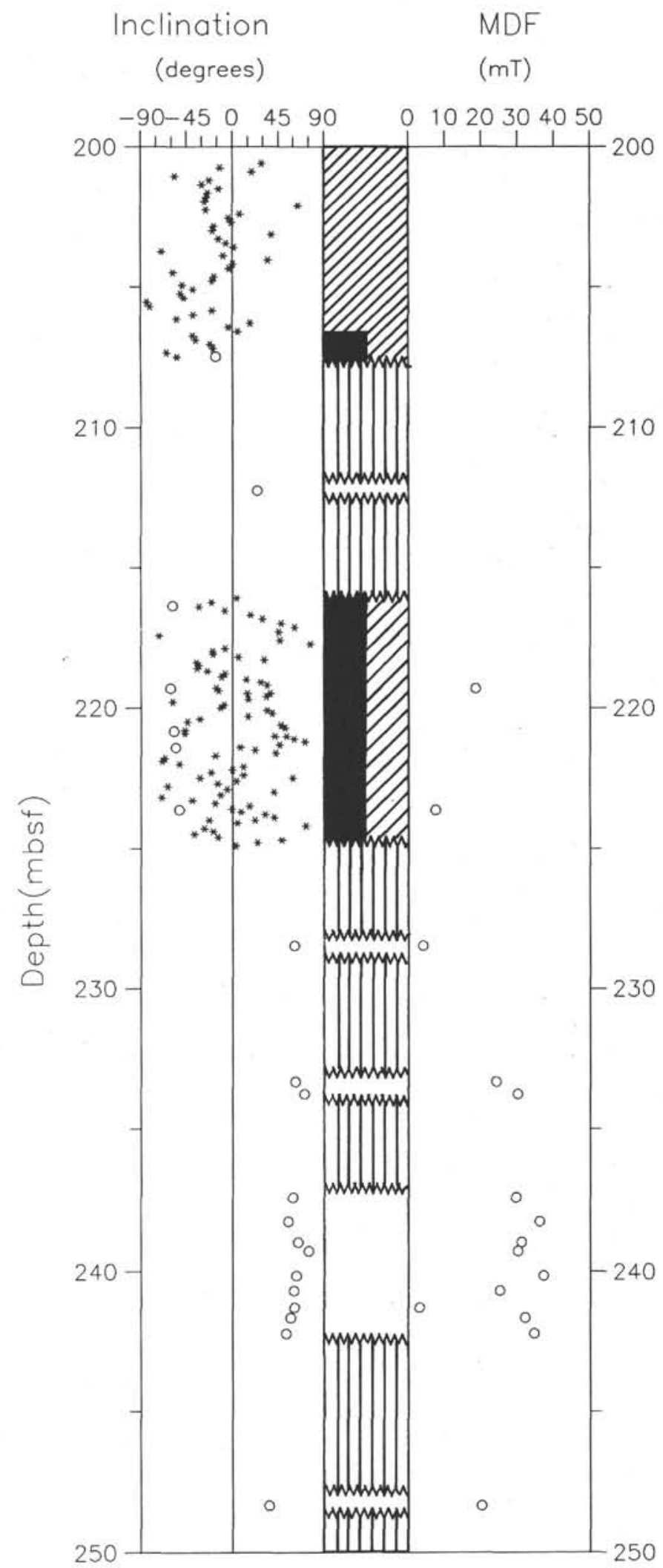

Figure 2 (continued). 
Chron C11, lies at 165 mbsf. The only difficulty is that the reversed interval between our proposed Chrons $\mathrm{C} 10$ and $\mathrm{C} 11$ is too short, compared with the standard reversal sequence. A normal-reversed-normal sequence is also found at Hole $747 \mathrm{C}$ between 160 and 165 mbsf. By comparing these results with the same depth interval in Hole $747 \mathrm{~A}$, the normals may be tentatively interpreted as the bottom of Chron $\mathrm{C} 10$ and the top of Chron C11. The magnetostratigraphy between 170.5 and 181.5 mbsf (Subunit IIC) cannot be considered as reliable as this nannofossil chalk was highly bioturbated. Neither could any useful information be obtained from the Maestrichtian volcaniclastic rocks between 181.4 and $197.2 \mathrm{mbsf}$. There seems to be part of a normal interval from 216 to $225 \mathrm{mbsf}$, which will require biostratigraphic control to identify.

It is clear from the above that the best paleomagnetic results were obtained from the nannofossil oozes recovered by APC coring. The quality of the magnetostratigraphy declined rapidly when XCB coring was used for the harder sedimentary sequences. The characteristic inclinations obtained from the single sediment cubes after AF demagnetization were generally steeper than the inclinations measured after 9-mT AF treatment during Leg 120. One explanation is that AF demagnetization on the ship was not sufficient to isolate the characteristic remanence and their inclinations. The second more likely explanation is that an inclination error occurred when the sediments were compacted as they dried in the plastic sample cubes, even during storage in the refrigerator. One would obtain a flattened magnetization as a result of sediment compaction in the horizontally stored cube, which had been pressed into a vertical cut through the core. One result of drying in the sample cube is a steeper inclination.

The highest median destructive fields $(25-45 \mathrm{mT})$ were measured on NRMs from the first 42 mbsf. This may be a result of a higher SD particle content in the top $42 \mathrm{~m}$ of the sediment column in Holes 747A and 747B. We saw a decrease in magnetic intensity from 20 to $2 \mathrm{~mA} / \mathrm{m}$ between 40 and 50 mbsf, which may be associated with a dissolution of the small magnetic particles (Karlin and Levi, 1985). Below 50 mbsf the MDF values are generally lower (around 10-25 mT) until they increase again below 232 mbsf. We will investigate how representative these MDF values of the NRM are for the ensemble of magnetic particles within one sample in a later section dealing with rock magnetic properties.

\section{Site 749}

The AF demagnetization experiments of single samples from Hole 749B confirmed the results obtained on board JOIDES Resolution between 8 and 16 mbsf. No additional information could be obtained for the magnetostratigraphy from discrete sample measurements at this site.

\section{Site 751}

Hole 751A was drilled in the Raggatt Basin on the Southern Kerguelen Plateau $\left(58^{\circ} \mathrm{S}\right)$. The top $1.5 \mathrm{mbsf}$ of Hole $751 \mathrm{~A}$ have normal magnetic polarity (Fig. 3). The inclinations of the section between 1.5 and 26.7 mbsf could not be interpreted since they were generally too shallow or missing. Part of these uninterpretable data can possibly be explained by core disturbance caused by porcellanitic chert pieces found between 10 and 25 mbsf (Schlich, Wise, et al., 1989). The chert pieces result from a layer of chert that shattered during drilling. The median destructive fields between 0 and about 40 mbsf were consistently high around $38 \mathrm{mT}$. These high MDFs correlate well with lithologic Unit I which consists mainly of diatom ooze. In lithologic Unit II (40.1-166.2 mbsf), nannofossil ooze predominates, and there is a noticeable drop in MDF to $<20$ $\mathrm{mT}$ below $40.1 \mathrm{mbsf}$. This drop in MDF between 40 and 60 mbsf suggests a different magnetic mineralogy on the top of Unit II.

From the biostratigraphic information presently available, we interpreted the normal interval between 36.7 and $40.1 \mathrm{mbsf}$ tentatively as part of Subchron C3A using the last appearance datum of $C$. $i$. triangularis, etc. (D. Lazarus, pers. comm., 1989). There should be a hiatus (5.75-8.0 m.y.) between 40.2 and 42.7 mbsf inferred from biostratigraphic results (Schlich, Wise, et al., 1989) and therefore Chron C4 is missing. An even longer hiatus, also with Chron C4 missing, was observed in Hole $747 \mathrm{~A}$ (see Fig. 2). We interpret the normal interval between 44 and 48.4 mbsf as part of Subchron C4A. The short reversed interval at 51.7 mbsf is best correlated to the short reversed period above Chron C5. The normal of Chron C5 stretches from 51.7 mbsf down to at least 69.2 mbsf. Between 71 and 98 mbsf the magnetization intensity measurements of single samples were too low to give any interpretable results.

The incomplete normal interval above 99.3 mbsf could be part of Chron C5A. It is difficult to interpret the inclinations between 100 and 110 mbsf because of the low intensities of magnetization and the present lack of biostratigraphic information. The hiatus that was suggested in the sedimentation rate curve (Schlich, Wise, et al., 1989) occurs at about 110 mbsf, as there is a change in magnetization intensity by about a factor of 15. A change in foraminiferal faunas places the unconformity at 109.2 mbsf (W. A. Berggren, pers. comm., 1989). The short normals between 110 and 112 mbsf may be Subchron C5B. We propose that Subchron C5C lies between 114.1 and 123.3 mbsf. If Chron C5D starts at 132.8 mbsf, then there are two short normal intervals at 127.5 and 129.0 mbsf that are not found on the geomagnetic polarity time scale (e.g., Berggren et al., 1985). The normal between 132.8 and 134.8 mbsf is too short to represent the complete Chron C5D at a sedimentation rate of about $20 \mathrm{~m} / \mathrm{m}$.y. Therefore, the end of the normal of Subchron C5D may not be reached yet at 136 mbsf. The top of Subchron C5E lies at $152.1 \mathrm{mbsf}$, as reported in the initial report (Schlich, Wise, et al., 1989). The MDFs of the NRMs of separate samples between 110 and $157 \mathrm{mbsf}$ were consistently high, ranging from 35 to $50 \mathrm{mT}$. A rock magnetic investigation in a later section of this paper will characterize the domain state of the magnetic minerals.

\section{Comparison of Paleomagnetic Parameters}

Histograms were prepared of NRM intensity, characteristic inclination and declination, initial susceptibility, and median destructive field of NRM for the investigated single samples. The distribution of NRM intensities for all samples from Hole 747A (Fig. 4) is centered on $1 \mathrm{~mA} / \mathrm{m}$ well above the noise level $(0.03 \mathrm{~mA} / \mathrm{m})$ of the magnetometer. The samples from Hole 751A (Fig. 5) show one peak in NRM intensity at $0.6 \mathrm{~mA} / \mathrm{m}$ and a second peak at $0.02 \mathrm{~mA} / \mathrm{m}$ below the sensitivity of the magnetometer. The characteristic inclinations in Holes $747 \mathrm{~A}$ and $751 \mathrm{~A}$ show bimodal distributions with maxima around $+65^{\circ}$ and $-65^{\circ}$, which is slightly lower than the inclination of $72^{\circ}$ expected for the present latitude of the sites. The inclinations of the single samples at both sites were on average about $15^{\circ}$ steeper than the inclinations measured on the ship. One possible explanation is that higher AF demagnetization levels on land were required to isolate the characteristic remanence, which is shallower than the inclination expected at the site, assuming a geocentric axial dipole field. An inclination error (shallowing) is usually not found in deep-sea sediments that are thought to carry postdepositional DRMs (Verosub, 1977). A second explanation for the steeper inclinations in the single samples could be the compaction of the sediment in the horizontally stored plastic cubes, which leads to higher inclination values (see Site 747). 
Hole 751A

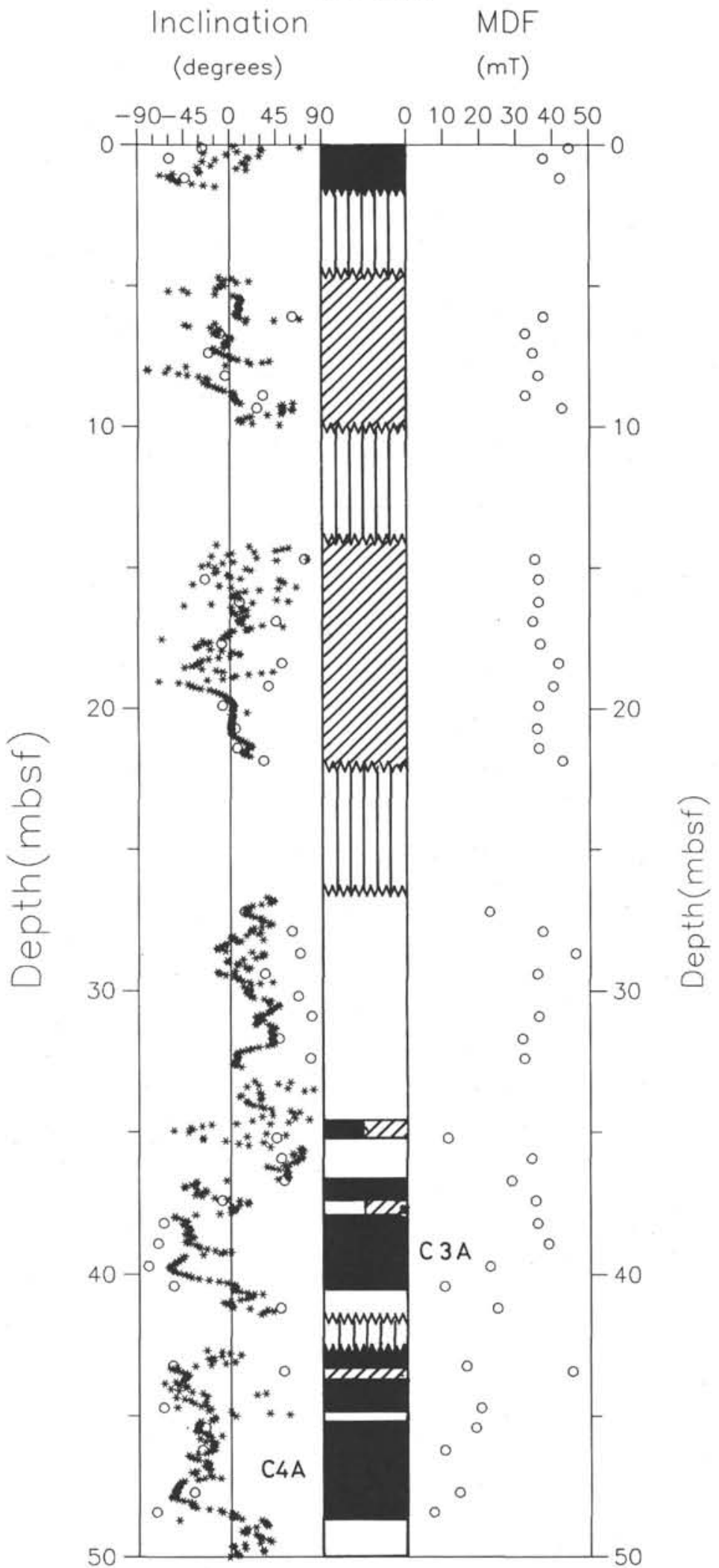

Hole $751 \mathrm{~A}$

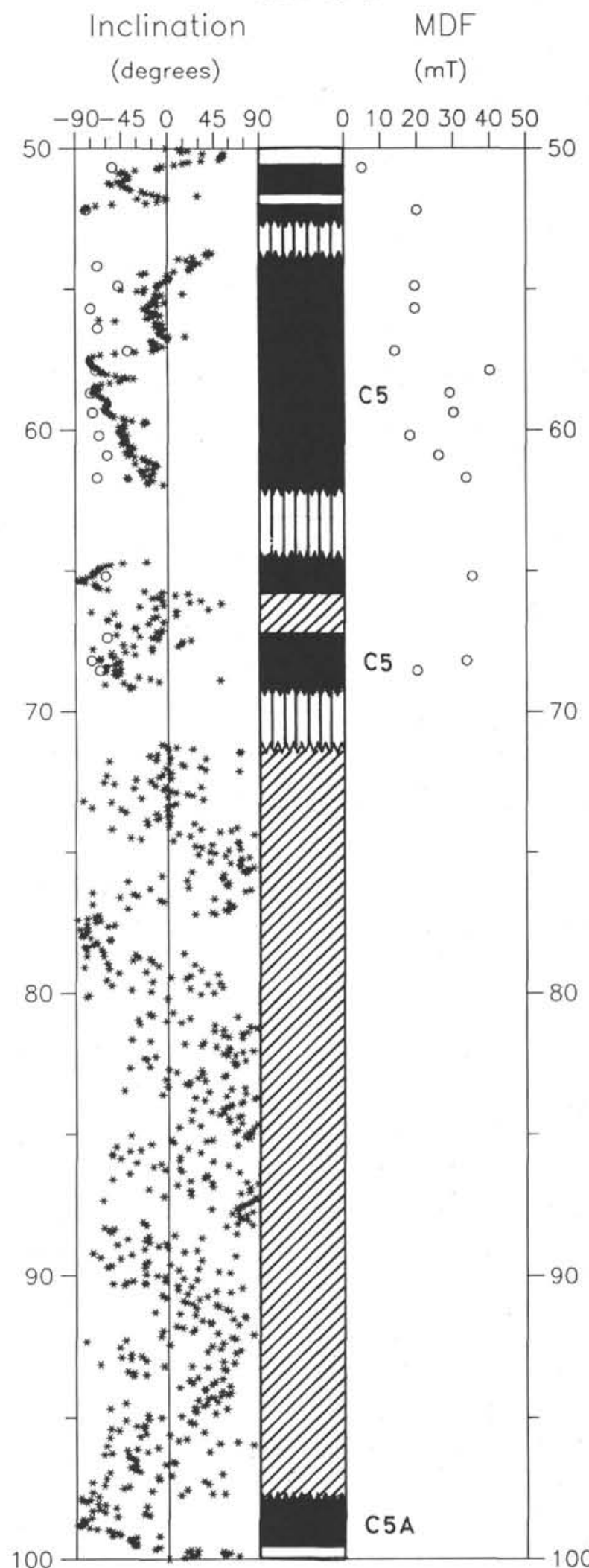

Figure 3. Depth plots of inclinations, interpretation in terms of magnetic reversals and median destructive fields (MDFs) for sediments from Hole $751 \mathrm{~A}(0-170 \mathrm{mbsf})$. For an explanation of the symbols used, see Figure 2. 
Hole $751 \mathrm{~A}$

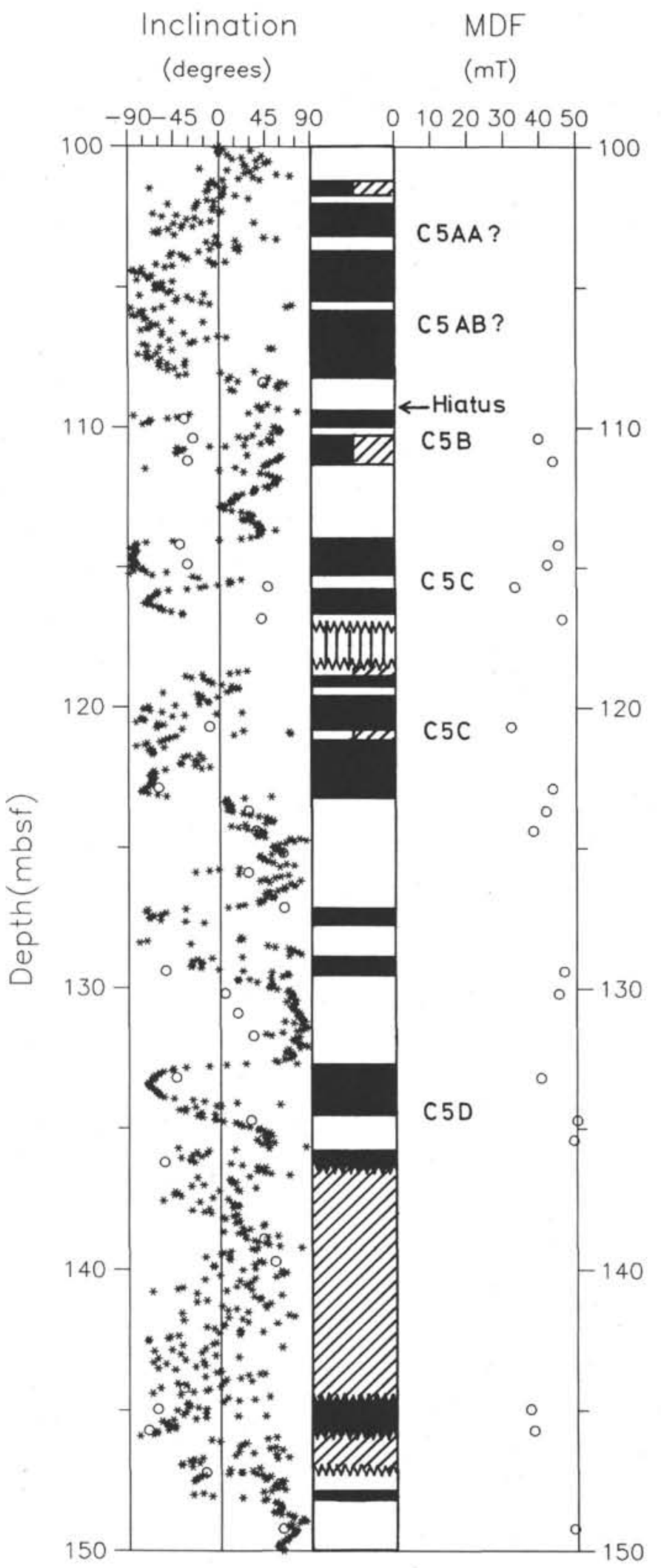

Hole 751A

$\begin{array}{cc}\text { Inclination } & \text { MDF } \\ \text { (degrees) } & (m T)\end{array}$

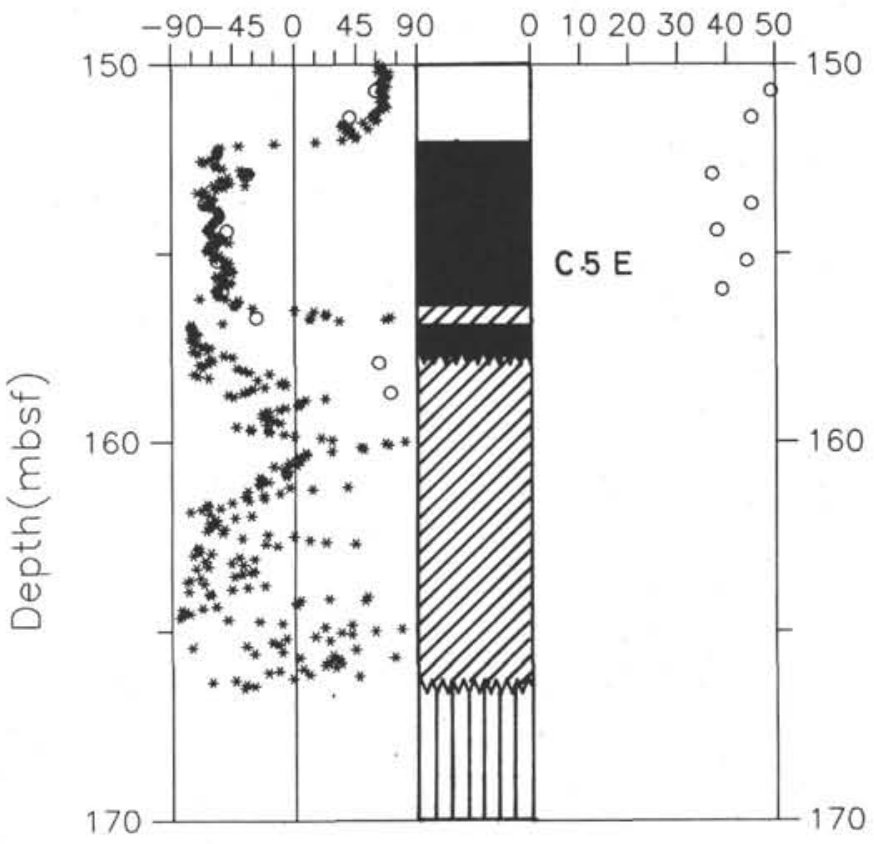

Figure 3 (continued). 

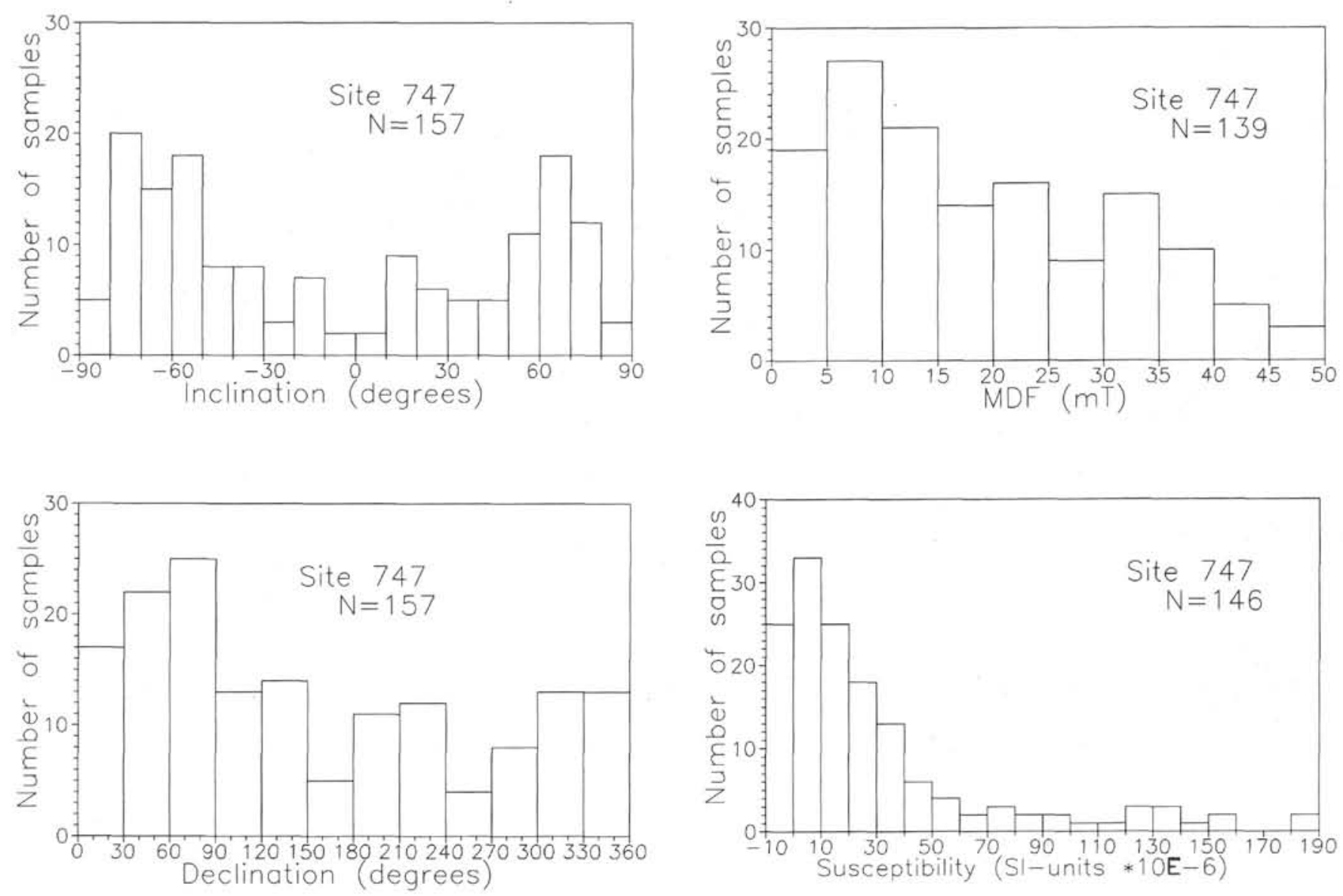

Figure 4 (continued).

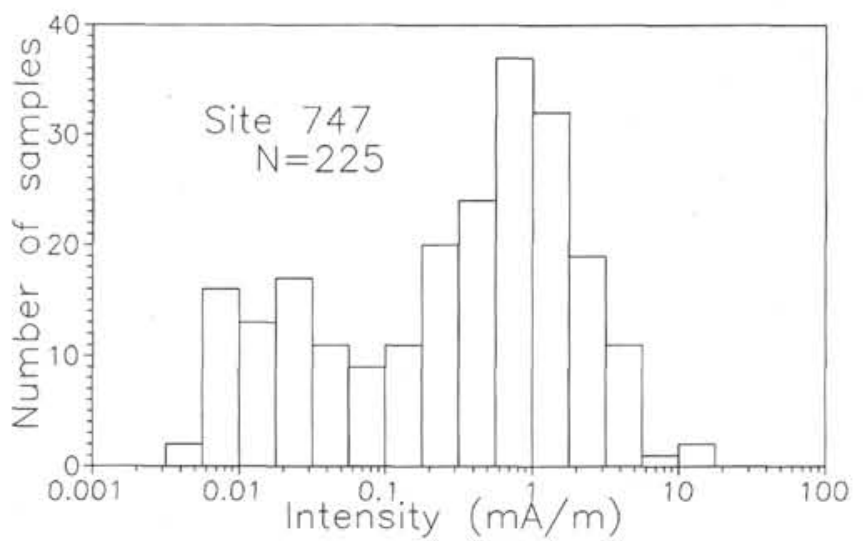

Figure 4. Histograms of paleomagnetic parameters determined from single-sediment samples of Hole 747A. The intensities are for natural remanent magnetizations (NRMs). Characteristic inclinations and declinations were determined from vector projections (see Fig. 1). Most NRM intensities were sufficiently high for AF demagnetization. The inclinations show a nearly bimodal distribution. $\mathrm{MDF}=$ median destructive field.

The distribution of declinations of samples from Sites 747 and 751 (Figs. 4 and 5) is not random as expected for unoriented cores. There is a slightly higher occurrence of declinations around $90^{\circ}$. An even more pronounced clustering of declinations was observed in the shipboard results and was interpreted as being caused by a secondary component of

magnetization acquired in the laboratory magnetic field within $2 \mathrm{hr}$ between splitting of the core and the measurement of its remanence. A similar post-splitting overprint with high coercivity values was found in Neogene cores from the Arctic Ocean by Witte and Kent (1988).

The initial susceptibilities of samples from Hole 747A were on average higher than the ones from Hole 751A. Negative susceptibilities result from diamagnetism of the calcium-carbonate-rich sediments. The median destructive fields of the NRMs range from 0 to $50 \mathrm{mT}$ at Hole $747 \mathrm{~A}$ with a maximum of the MDF distribution around $10 \mathrm{mT}$. The low MDFs at 10 mT possibly represent a viscous component carried by a soft magnetic phase that is easily demagnetized. The MDFs of NRMs from Hole 751A cluster around $35 \mathrm{mT}$. These high MDFs point toward a hard magnetic phase, possibly of single-domain origin.

\section{ROCK MAGNETISM}

We carried out a series of rock magnetic investigations on sediment cubes to identify and characterize the carriers of magnetization. Seven samples were selected from Hole 747A and four samples from Hole 751A. Sufficiently high susceptibility and differences in lithology and AF demagnetization characteristics were used as a selection criterion.

First, we present IRM induction curves to identify the magnetic phases, even though the IRMs had been induced after the ARM experiments were finished. Isothermal remanent magnetizations were induced stepwise in direct magnetic fields (DF) up to $1.5 \mathrm{~T}$ (Fig. 6). Nine of the eleven samples had IRM induction curves that were over $90 \%$ saturated at 300 

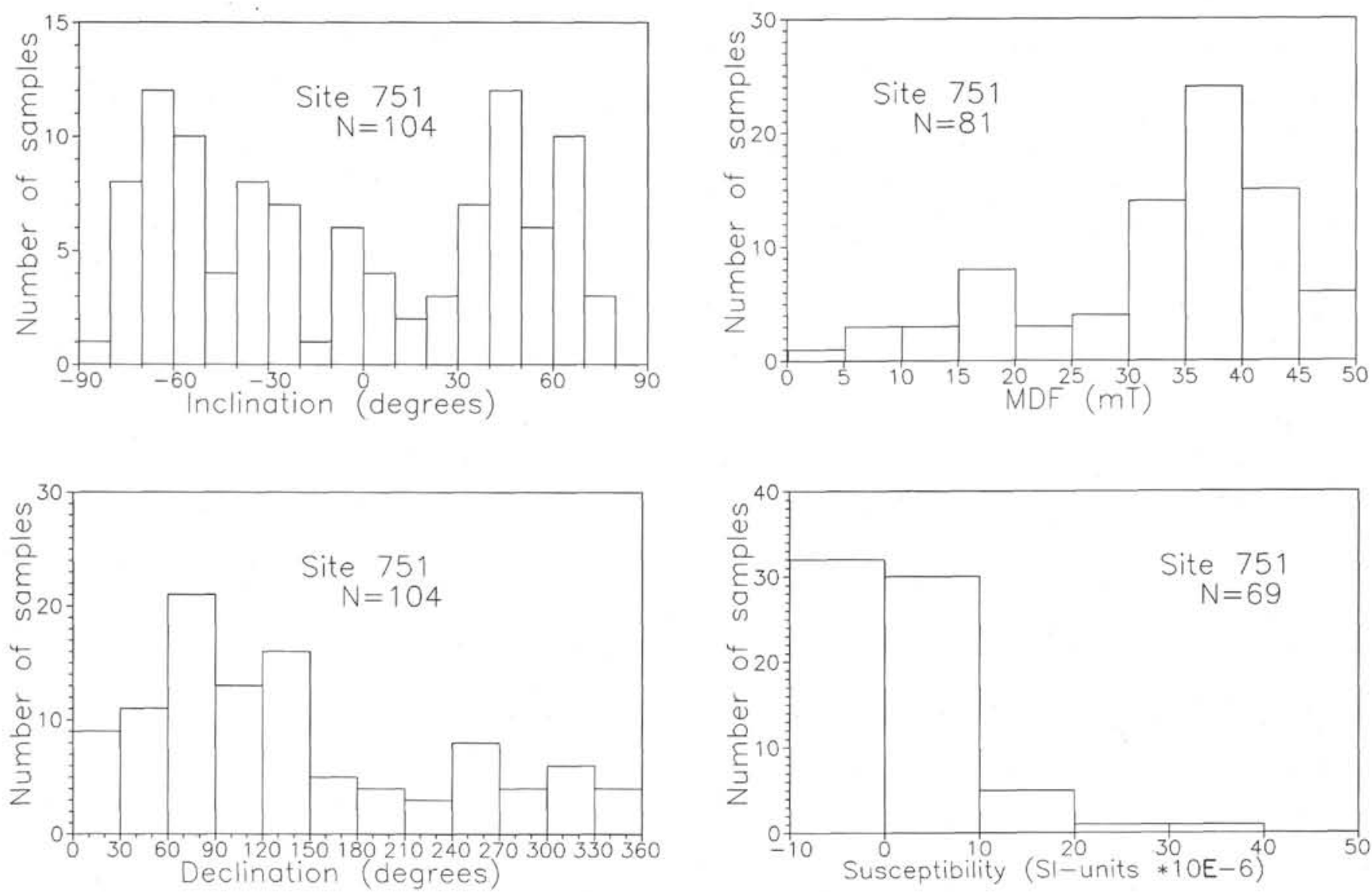

Figure 5 (continued).

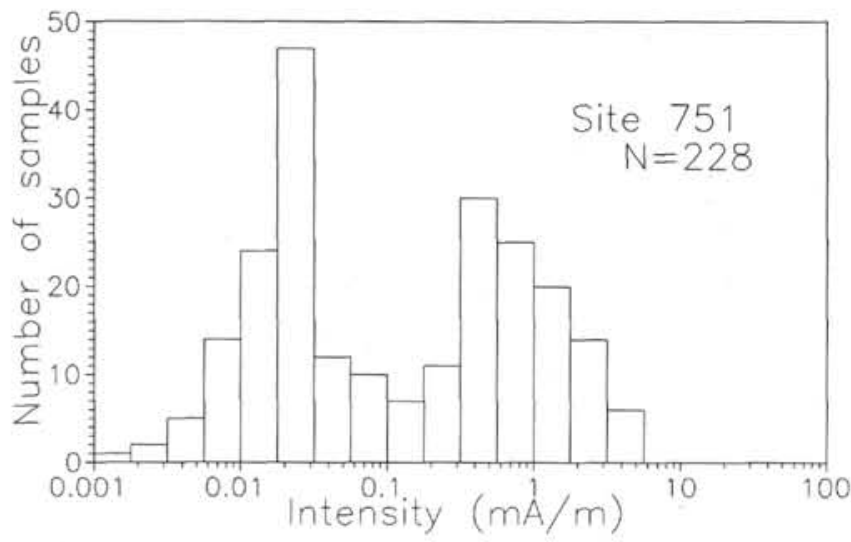

Figure 5. Distribution of paleomagnetic parameters for Hole 751A. A major fraction of the samples had NRM intensities below the sensitivity $(0.03 \mathrm{~mA} / \mathrm{m})$ of the cryogenic magnetometer. Characteristic inclinations could be determined for 104 out of 228 samples. MDF = median destructive field.

$\mathrm{mT}$. This relatively fast approach to saturation, which reaches a plateau above $300 \mathrm{mT}$, is indicative of magnetite or an $\mathrm{Fe}-\mathrm{Ti}$ spinel as the main magnetic mineral. There are two samples in Figure 6A (120-747A-16H-6, 32-34 cm, and 120-747A-18X-2, $96-98 \mathrm{~cm}$ ) that reach saturation much slower. These two samples probably contain an additional magnetic phase with high coercivity values.

A Lowrie-Fuller test (Lowrie and Fuller, 1971; Bailey and Dunlop, 1983; Heider, 1988) was performed to determine the domain state of the magnetic minerals. All samples were given

anhysteretic remanent magnetization with a $160-\mathrm{mT}$ peak alternating field and a 0.1 - or $2-\mathrm{mT}$ bias field. After AF demagnetization of the ARMs, the samples were given isothermal remanent magnetization with 160 or $100 \mathrm{mT}$. A comparison of the AF demagnetization curves showed that for all 11 samples the ARMs were more resistant to AF treatment than the IRMs (Fig. 7). This result suggests that the magnetic grains are in a single-domain (SD) or pseudo-single-domain (PSD) state.

We did not use a saturation isothermal remanent magnetization (SIRM) for comparison with the ARM. Instead, we used the same field strengths for the direct and alternating fields during IRM and ARM induction, respectively, to activate grains with the same coercive forces. Furthermore, we wanted to avoid the magnetization of a high coercivity phase that could not be demagnetized with the available alternating fields. For example, Sample 120-747A-18X-2, 96-98 cm, has a second magnetic phase with high coercivity values, as shown by the IRM induction curves above. The Lowrie-Fuller test in the conventional sense using an $\operatorname{SIRM}(H=1.5 \mathrm{~T})$ is therefore not applicable to a sample with a spinel and a high coercivity phase (see Fig. 7B).

A comparison of the AF demagnetization behavior of the IRMs of all 11 samples is shown in Figure 8. The samples from Hole 747A (Fig. 8A) have very similar demagnetization curves with MDFs between 20 and $28 \mathrm{mT}$. In Hole $751 \mathrm{~A}$, the four samples can be divided into two groups with different $\mathrm{AF}$ demagnetization properties (Fig. 8B). The upper two samples from Cores $120-751 \mathrm{~A}-2 \mathrm{H}$ and $-3 \mathrm{H}$ (Unit I) are more easily AF demagnetized than the lower two samples from Cores 120 $751 \mathrm{~A}-14 \mathrm{H}$ and $-15 \mathrm{H}$ (Unit II). The two samples from the 

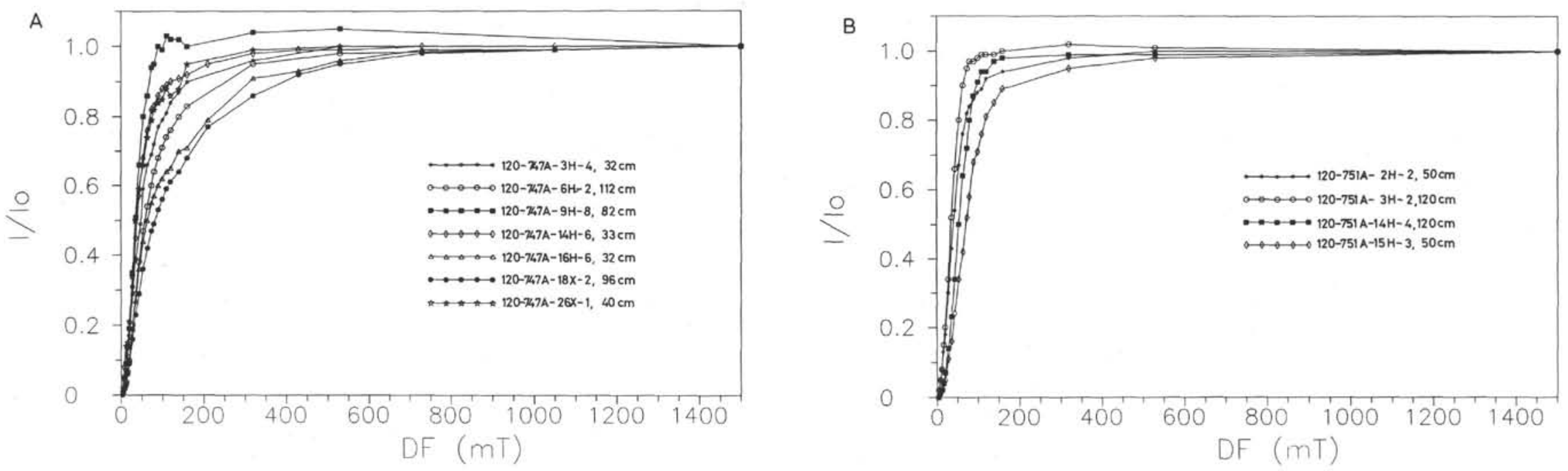

Figure 6. Acquisition curves of isothermal remanent magnetization (IRM) normalized to the saturation value at 1.5-T direct field. A. The seven samples from Hole 747A have IRM acquisition curves characteristic for Fe-Ti spinels with the exception of Samples 120-747A-16H-6, 32-34 cm, and 120-747A-18X-2, 96-98 cm, which have an additional phase with high coercivity values. B. All four samples from Hole 751A have "magnetite-like" IRM acquisition behavior. 

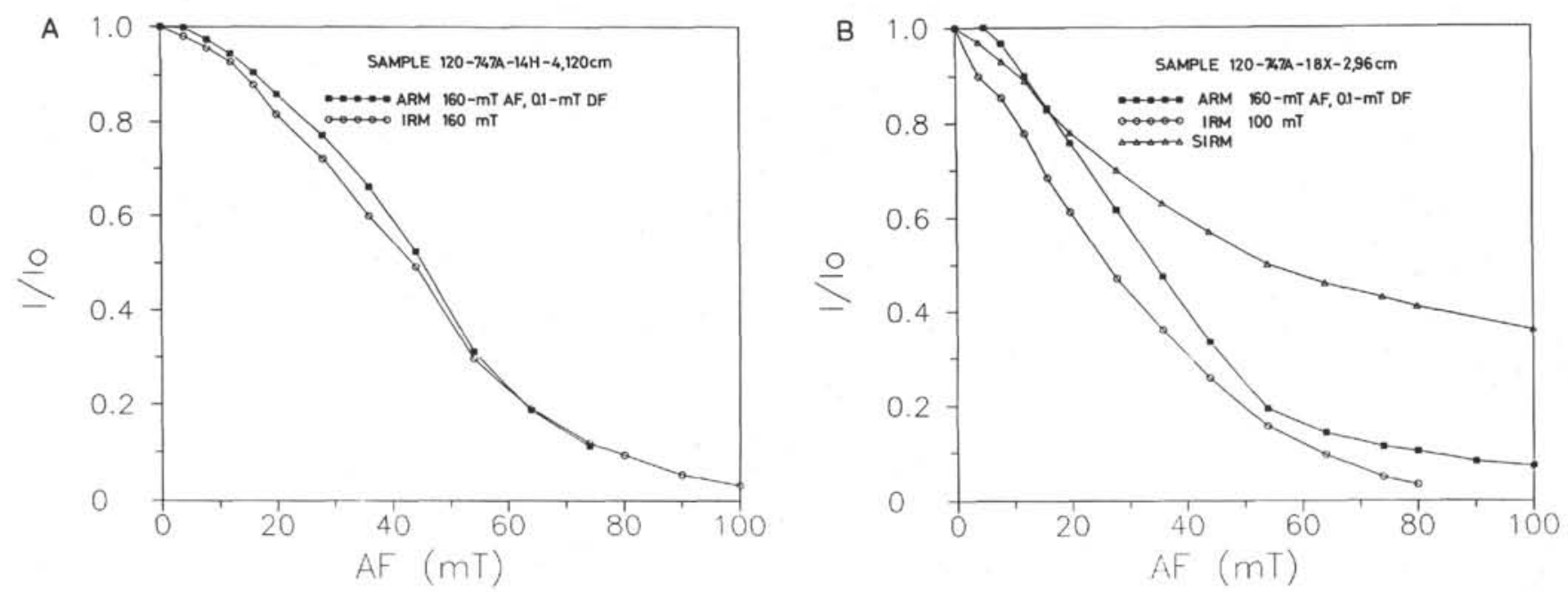

Figure 7. Alternating field (AF) demagnetization of anhysteretic remanent magnetizations (ARMs) and isothermal remanent magnetizations (IRMs). A. The ARM of Sample 120-747A-14H-4, 120-122 cm, is more resistant to AF demagnetization than the IRM. This result of a Lowrie-Fuller test is characteristic for single-domain/pseudo-single-domain (SD/PSD) size grains. B. Same result as in Figure 7A for ARM and IRM. Only the saturation IRM of Sample 120-747A-18X-2, 96-98 cm, is much harder than the IRM because of a second magnetic phase with high coercivity values.
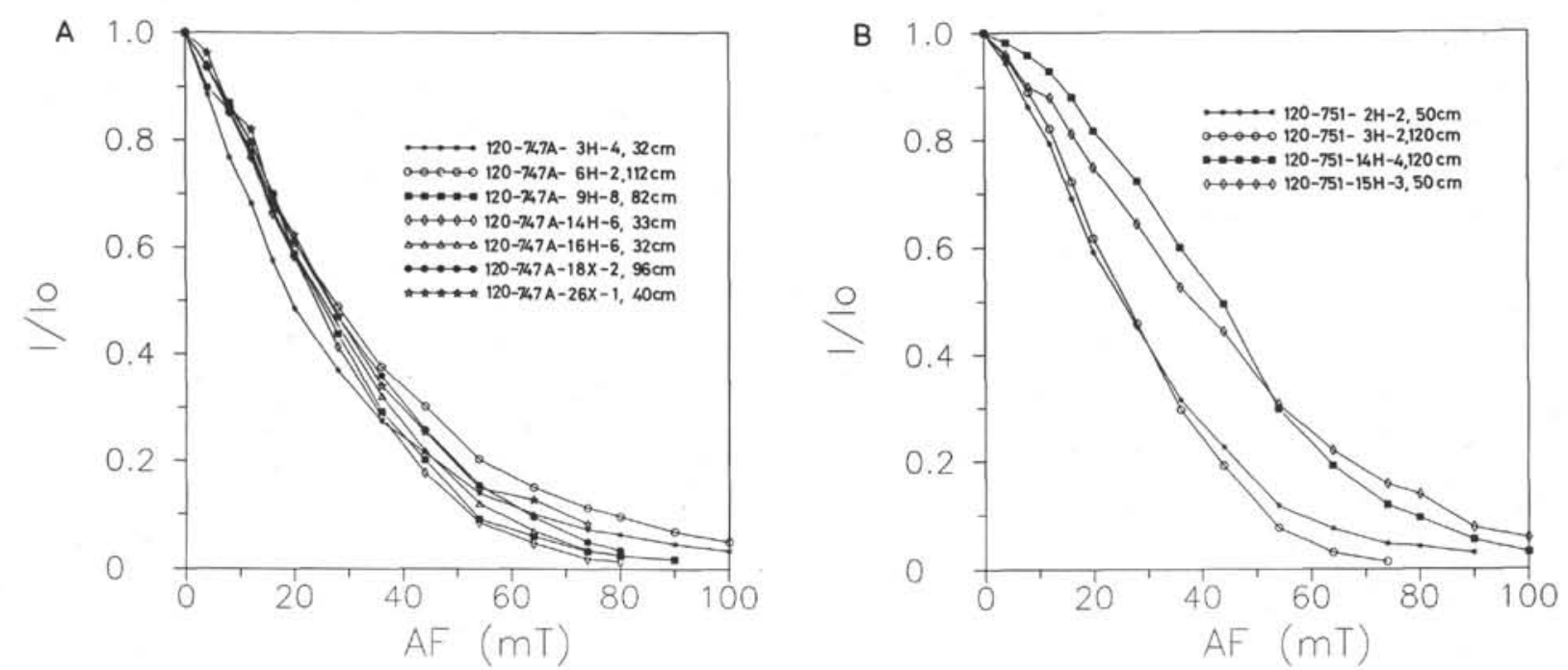

Figure 8. Alternating field (AF) demagnetization of isothermal remanent magnetizations (IRMs). A. The seven samples from Hole 747A have similar demagnetization curves and therefore similar coercivity distributions. B. The four samples from Hole 751A can be divided into two groups based on their AF demagnetization characteristics. The lower two samples from Cores 120-751A-14H and $-15 \mathrm{H}$ behave like single-domain particles during demagnetization.

Pliocene diatom ooze have softer magnetic remanence carriers than the two samples from the diatom nannofossil ooze of early Miocene age. Despite this difference, all four samples from Site 751 have SD- or PSD-like demagnetization curves (MDF $>25 \mathrm{mT}$ ) distinctly different from the much softer multidomain (MD) AF demagnetization behavior of magnetite (MDF $<10 \mathrm{mT}$ ) (Heider, 1988). Similar groupings to the ones in Figures $8 \mathrm{~A}$ and $8 \mathrm{~B}$ were found for the $\mathrm{AF}$ demagnetization curves of ARMs in the 11 samples.

The coercivity of remanence $H_{c r}$ was determined from the intersection of the AF demagnetization curve of an SIRM with the SIRM induction curve (Cisowski, 1981). An example for this method is given in Figure 9. We verified on five test samples that demagnetization of an SIRM with a reverse direct field gave the same results for $H_{c r}$ as the intersection method.

Hysteresis parameters were obtained from hysteresis loops (Fig. 10) for a determination of the magnetic domain state. Of interest were the coercive force $H_{\mathrm{c}}$ and the ratio of saturation remanence $I_{r s}$ over saturation magnetization $I_{s}$. In Figure 10 there is a small contribution of the diamagnetic carbonates to the hysteresis loop that leads to a decrease in magnetization once the ferrimagnetic phase has reached saturation. We corrected our hysteresis parameters for the varying diamagnetic contributions. Nine of the 11 samples contained sufficient ferrimagnetic material for a determination of hysteresis parameters. Following the method of Day et al. (1977), we plotted the $I_{r s} / I_{s}$ ratios vs. $H_{c r} / H_{c}$ (Fig. 11). The results from all 
samples lie in the field, which is characteristic for small PSD particles close to the SD region. Multidomain grains of magnetite above $10 \mu \mathrm{m}$ in diameter have $I_{r s} / I_{s}<0.006$ and $H_{c r} / H_{c}$ ratios around 25 (Heider et al., 1987). We will show with the low-temperature experiments below that some of the samples contain particles in the SP (superparamagnetic) size range. These small superparamagnetic particles $(d<0.03 \mu \mathrm{m})$ (Dunlop, 1981) lower the $I_{r s} / I_{s}$ values, which means that some of our samples have a major fraction of their magnetic grains in the SD state.

A summary of rock magnetic parameters as a function of sub-bottom depth is given in Figure 12 for Sites 747 and 751, respectively. For both sites there is a reasonable correlation between the $H_{c}, H_{c r}, \mathrm{MDF}_{\mathrm{ARM}}$, and $\mathrm{MDF}_{\text {SIRM }}$ depth dependence. High MDFs are expected for samples with high $H_{c r}$ and $H_{c}$ values. Unfortunately, this trend in $H_{c r}$ and the MDFs of ARM and SIRM is not reflected in the MDFs of the NRMs in Hole 747A and appears very weak at Hole 751A. One wonders, therefore, whether the magnetic fraction that carries the NRM is the same as the one investigated by the rock magnetic experiments. The low intensity of an NRM, which is typically 0.01-0.001 of the ARM in the same sample, suggests that NRMs are only recorded by a fraction of the available magnetic grains. The recording of the paleo-field direction in our sediments in the form of a DRM is a rather inefficient process compared with an ARM. The presence of a highcoercivity magnetic phase in two samples in Hole 747A is reflected by a gap between the MDFs of their SIRM and IRM (Fig. 12A). The MDFs of SIRM and IRM have similar values in samples with magnetite as the main magnetic mineral.

A magnetic viscosity test was carried out with the 11 samples. Immediately after SIRM induction, the magnetization was measured for the first time. The samples were stored in a field free $\mu$-metal shield and remeasured in logarithmic time increments from 1 to $10^{4} \mathrm{~min}$ (Fig. 13). All samples showed viscous decay of the SIRM. Samples 120-747A-3H-4, $32-34 \mathrm{~cm}, 120-747 \mathrm{~A}-9 \mathrm{H}-8,82-84 \mathrm{~cm}$, and $120-747 \mathrm{~A}-26 \mathrm{X}-1$, $40-42 \mathrm{~cm}$, had lost about $15 \%$ of their original SIRM after $10^{4}$ min (Fig. 13A). Samples 120-751A-14H-4, 120-122 cm, and $120-751 \mathrm{~A}-15 \mathrm{H}-3,50-52 \mathrm{~cm}$, were slightly more viscous than Samples 120-751A-2H-2, 50-52 cm, and 120-751A-3H-2, $120-$ $122 \mathrm{~cm}$ (Fig. 13B).

To investigate the magnetic domain structure and the origin of the viscous behavior, we performed two kinds of lowtemperature experiments. First, all samples were given an IRM $(H=100 \mathrm{mT})$ at $290 \mathrm{~K}$ and cooled down to $77 \mathrm{~K}$ and warmed up to room temperature in zero magnetic field. The remanence remaining after the low-temperature demagnetization cycle was measured at $290 \mathrm{~K}$ and the decrease in percent is shown in Table 1. In the case of magnetite, a zero or small decrease in magnetization after cooling through the point of zero magnetocrystalline anisotropy at $120 \mathrm{~K}$ corresponds to mainly SD particles, whereas a large decrease in IRM as in Samples 120-747A-26X-1, 40-42 cm, 120-751A-2H-2, 50-52 $\mathrm{cm}$, and $120-751 \mathrm{~A}-3 \mathrm{H}-2,120-122 \mathrm{~cm}$, implies that part of the remanence is carried by PSD and/or MD grains (Levi and Merrill, 1978). The four samples at Site 751 can be divided into two groups (see the center column of Table 1). The upper two samples partially show a PSD/MD-like, low-temperature demagnetization behavior, whereas the lower two samples behave SD-like. The same division of the four samples was found from a comparison of $H_{c}, H_{c r}$, and MDFs (Fig. 12B). This argument is only valid for titanomagnetite close to magnetite in composition because the critical temperature depends on the titanium content.

With the second low-temperature experiment, we wanted to look at the presence of particles that are in the superpara- magnetic size range. The SP particles can change to the SD state and possess a magnetic remanence at low temperatures on account of the decrease in thermal fluctuations. The 11 samples were given IRMs $(H=100 \mathrm{mT})$ at $77 \mathrm{~K}$, and these IRMs of the thermally insulated samples were measured at or close to liquid nitrogen temperature. We found that Samples $120-747 \mathrm{~A}-3 \mathrm{H}-4,32-34 \mathrm{~cm}$, and $120-747 \mathrm{~A}-9 \mathrm{H}-8,82-84 \mathrm{~cm}$, had the highest increase in IRM at $77 \mathrm{~K}$ compared with their room temperature IRM (see third column in Table 1). These two samples are also among the three most viscous samples (Fig. 13A). It is probably safe to assume that samples with a large fraction of SP grains contain small SD particles that are magnetically viscous, with relaxation times on the order of the laboratory time scale. A magnetic mineral with a Curie point below room temperature could be another cause for the increase in low-temperature IRM relative to an IRM at $290 \mathrm{~K}$. So far, we have no explanation for the decrease in IRM at 77 $\mathrm{K}$ in the lower two samples in Hole 751A.

\section{Magnetic Extracts from Sediments}

The magnetic fractions of our 11 sediment cubes were obtained by passing a liquid suspension of each sample for 1 week past a magnet with a strong field gradient. The magnetic extracts were first investigated by scanning electron microscopy (SEM) with attached energy dispersive X-ray analysis (EDA). Only a small fraction of the particles in the magnetic separate had iron among the cations and were potentially magnetic. These few particles with iron and titanium as major cations were from 5 to $\approx 70 \mu \mathrm{m}$ in size. Our interpretation that these particles are titanomagnetite and magnetite is supported by X-ray diffraction measurements with the Debye-Scherrer method. In the magnetic separates from three samples, we found the three strongest lines of (titano)magnetite. We also observed oxidized titanomagnetite particles with shrinkage cracks typically found in titanomaghemite from ocean-floor basalts (Petersen and Vali, 1987).

To our surprise, we found a large fraction of volcanic glass particles in all 11 samples. These glasses were recognized by spherical inclusions that had trapped gasses during cooling. The proximity of Sites 747 and 751 to the volcanic Heard and Kerguelen islands makes a continuous input of air-transported volcanic ash particles quite likely. These vitric volcanic ash grains very likely contain a ferromagnetic phase since they were extracted magnetically. Qualitative EDA of volcanic glass particles like the one in Figure $14 \mathrm{~A}$ showed $\mathrm{Fe}$ and some $\mathrm{Ti}$ among the cations $\mathrm{Si}, \mathrm{Ca}, \mathrm{Al}$, and $\mathrm{K}$. An enlargement of the particle in Figure 14A reveals a small cubic inclusion. The EDA of this $1-\mu \mathrm{m}$-size particle showed $\mathrm{Fe}$ as the major cation. We interpret this inclusion as an $\mathrm{Fe}$-oxide surrounded by a weathered rim. Basaltic glasses are known to contain microlites of Fe-Ti oxide (Fisher and Schmincke, 1984). Dark glass particles that contain small iron-titanium oxide crystallites are called tachylite. Small magnetite with low Ti content and PSD magnetic properties were found in obsidian material by Schmidbauer et al. (1986). Vali et al. (1989) found from EDA using an SEM that rock particles in magnetic separates contained inclusions of titanomagnetite up to $1 \mu \mathrm{m}$ in size. None of our analyses showed sulfur among the identified elements. We therefore exclude $\mathrm{Fe}-\mathrm{S}$ substances as possible magnetic minerals.

We prepared two additional magnetic separates from two sample cubes from Sections $120-747 \mathrm{~A}-3 \mathrm{H}-3$ and $120-747 \mathrm{~A}-$ $3 \mathrm{H}-5$ and Sections 120-747A-18X-1 and 120-747A-18X-3 for a detailed study of the volcanogenic component by P. Bitschene (Bochum University). The sample from Core 120-747A-3H contains material from a phonolithic eruption with a high content of crystalline grains and well-sorted vitric volcanic 


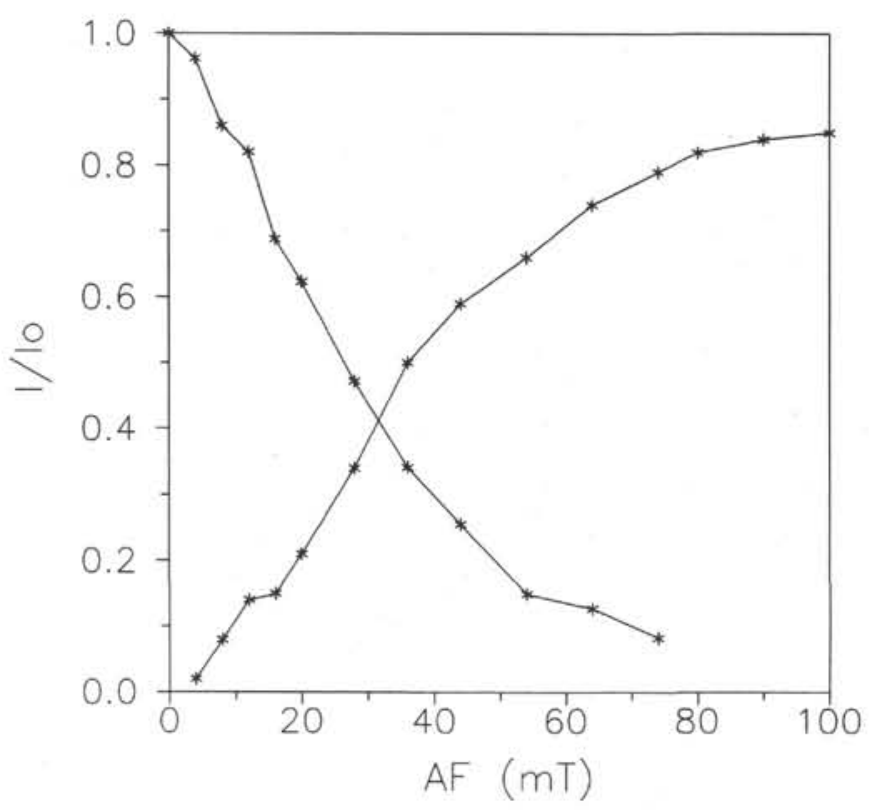

Figure 9. Acquisition of an isothermal remanent magnetization (IRM) and alternating field (AF) demagnetization of a saturation IRM (SIRM), both normalized to the remanence at $1.5 \mathrm{~T}$. (Sample 120$747 \mathrm{~A}-26 \mathrm{X}-1,40-42 \mathrm{~cm}$ ). The magnetic field at the intersection of both curves was found to be equal to the remanent coercivity $H_{c r}(\mathrm{Ci}-$ sowski, 1981).

ash particles as seen from a polished thin section. The narrow grain-size distribution $(50 \pm 20 \mu \mathrm{m})$ points to subaerial fallout as the source of these ashes. The glasses can be subdivided into (1) light-brown phonolithic glasses with hematite in cracks; (2) dark-brown basaltic glasses with $1-5-\mu \mathrm{m}$-size magnetite; and (3) tachylite, which is opaque because of the submicroscopic crystallization of Fe-Ti oxides. The sample from Core 120-747A-18X contains vitric ash particles, which are extremely well sorted $(60 \pm 20 \mu \mathrm{m})$. The glasses consist of (1) about $50 \%$ tachylite, opaque with reddish appearance on the semitranslucent rim; (2) $30 \%$ altered basaltic glasses; and (3) $10 \%$ fresh basaltic glasses. The red microlite component in the tachylite-possibly hematite-may well be the hard magnetic phase found in Sample 120-747A-18X-2, 96-98 cm, from IRM induction and AF demagnetization of an SIRM (Figs. 6A and 7B). A detailed investigation of the volcanic glass particles with microprobe and TEM is underway and will be presented elsewhere.

We mounted magnetic extracts from Samples 120-747A$3 \mathrm{H}-4,32-34 \mathrm{~cm}, 120-747 \mathrm{~A}-6 \mathrm{H}-2,112-114 \mathrm{~cm}, 120-747 \mathrm{~A}-$ $18 \mathrm{X}-2,96-98 \mathrm{~cm}$, and 120-751A-2H-2, 50-52 cm, on copper grids for transmission electron microscopy (TEM) following a method described by Petersen et al. (1986). The aim of the TEM investigation was to look for biogenic magnetite, which is readily identified by the shape and size of the particles and the tendency of magnetofossils to form chains. We found no evidence for SD magnetite particles of biogenic origin in the four sediment extracts that we studied. This finding does not prove the absence of magnetofossils in Neogene sediments from the Kerguelen Plateau, but it does mean that other sources of small magnetic particles should be considered for this part of the South Indian Ocean.

Support for $\mathrm{Fe}-\mathrm{Ti}$ oxides as the main magnetic mineral comes from Curie temperature determinations. In two cases, the cooling curves in $I_{s}(\mathrm{~T})$ experiments showed higher saturation magnetization than the heating curves, which is an

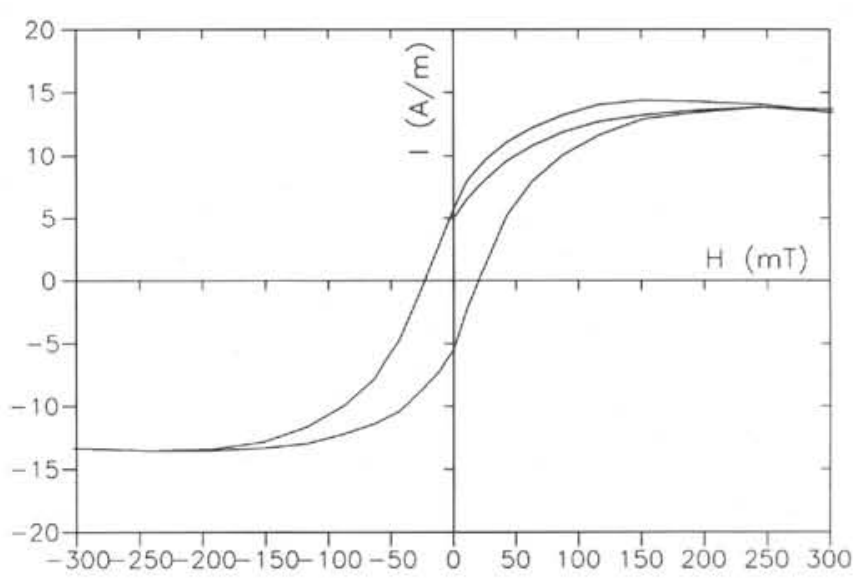

Figure 10. Magnetic hysteresis loop measured with a translation hysteresis balance. The measurement was performed on a piece of the original sediment (Sample 120-747A-6H-2, 112-114 cm) and not on a magnetic separate.

indication for titanomagnetite transforming into stronger magnetic magnetite above $200^{\circ} \mathrm{C}$. Sample $120-747 \mathrm{~A}-3 \mathrm{H}-4,32-34$ $\mathrm{cm}$, had a Curie point of about $175^{\circ} \mathrm{C}$, which is characteristic of a titanomagnetite with $60 \% \mathrm{Ti}$ content. The Curie temperature determinations also showed Curie points between $530^{\circ}$ and $580^{\circ} \mathrm{C}$, but it is difficult to judge if the corresponding magnetite is a primary phase or if it was produced during heating.

\section{CONCLUSIONS}

The preliminary magnetostratigraphy that was determined during Leg 120 could be confirmed with the landbased stepwise AF demagnetization of single samples. The top of Chron C3 was located in Hole 747B. The top of Chron C5 was not found, but the short normal interval (C4An3) above Chron C5 was found at 45.5 mbsf in Hole $747 \mathrm{~A}$. The bottom of Chron C5 is now undetermined in Hole $747 \mathrm{~A}$, but it may be visible at Hole 747B at 49.9 mbsf. The two normal intervals of C5A were shifted slightly upward. Furthermore, we determined the upper normal interval of Chron C6A and the bottom of Chron $\mathrm{C} 10$ in Hole $747 \mathrm{~A}$. The reversal sequence of Hole $751 \mathrm{~A}$ was reinterpreted around $50 \mathrm{mbsf}$ and requires confirmation by correlation with biostratigraphic findings. Major parts of the magnetostratigraphy in Hole 751A could be determined down to Chron C5E at 155 mbsf. We have no more evidence for the presence of Chron C6 in our magnetic record in Hole 751A.

The rock magnetic investigation showed that titanomagnetites with varying $\mathrm{Ti}$ content are the main magnetic minerals in different lithologic units of Sites 747 and 751. A detrital origin of the carriers of the stable natural remanent magnetization is therefore very likely. Two out of 11 samples had an additional high coercivity phase, which could be hematite. Lowrie-Fuller tests, hysteresis measurements, and low-temperature (77 K) experiments were carried out. The magnetic domain state for all investigated samples was determined as SD to small PSD with occasional superparamagnetic contributions. Two samples with high SP grain-size fractions were among the most viscous samples. We conjecture that particles just above the SP/SD boundary with relaxation times on the order of minutes are the most likely candidates for the magnetic viscosity. A large fraction of volcanic glass particles was concentrated in the magnetic separates. These volcanic glass particles may be magnetic because of submicron precipitate (microlite) of tita- 


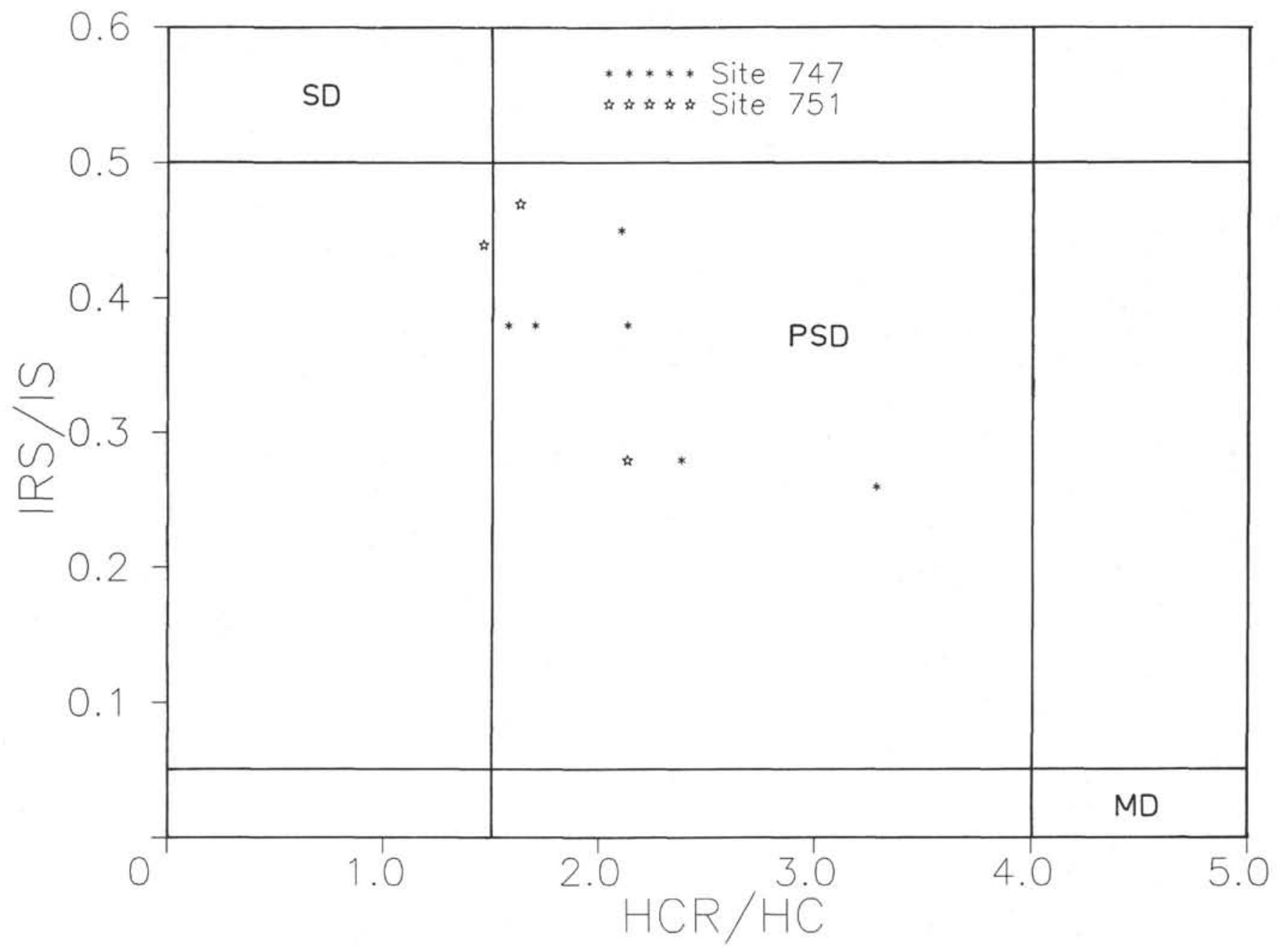

Figure 11. Diagram of reduced saturation remanence $I_{r s} / I_{s}$ vs. the coercivity ratio $H_{c r} / H_{c}$ after Day et al. (1977). $I_{r s}$ is saturation remanence, $I_{s}$ is saturation magnetization, $H_{c r}$ is coercivity of remanence, and $H_{c}$ is coercive force. The results from the sediments of Sites 747 and 751 plot in an area characteristic of small pseudo-single-domain (PSD) particles. The samples with $I_{r s} / I_{s}$ ratios close to 0.5 contain a major fraction of particles in the single domain (SD) state, if one considers the presence of superparamagnetic grains. $\mathrm{MD}=$ multidomain.

nomagnetite and hematite that are known to occur in basaltic glasses.

\section{ACKNOWLEDGMENTS}

Financial support and travel funds from D. J. Dunlop (Toronto) and from ODP Germany are gratefully acknowledged. We thank Thilo von Dobeneck for use of his translation hysteresis balance and N. Petersen, H. C. Soffel, J. Froh (Munich), and H. Vali (Montreal) for advice and discussions. The cooperation of P. Bitschene (Bochum) during the investigation of the volcanic ashes.was highly appreciated.

\section{REFERENCES}

Bailey, M. E., and Dunlop, D. J., 1983. Alternating field characteristics of pseudo-single-domain (2-14 $\mu \mathrm{m})$ and multidomain magnetite. Earth Planet. Sci. Lett., 63:335-352.

Berggren, W. A., Kent, D. V., Flynn, J. J., and Van Couvering, J. A., 1985. Cenozoic geochronology. Geol. Soc. Am. Bull., 96:14071418.

Cisowski, S., 1981. Interacting vs. non-interacting single domain behavior in natural and synthetic samples. Phys. Earth Planet. Inter., 26:56-62.
Day, R., Fuller, M., and Schmidt, V. A., 1977. Hysteresis properties of titanomagnetites: grain-size and compositional dependence. Phys. Earth Planet. Inter., 13:260-267.

Dunlop, D. J., 1981. The rock magnetism of fine particles. Phys. Earth Planet. Inter., 26:1-26.

Fisher, R. V., and Schmincke, H.-U., 1984. Pyroclastic Rocks: New York (Springer-Verlag).

Heider, F., 1988. Magnetic properties of hydrothermally grown $\mathrm{Fe}_{3} \mathrm{O}_{4}$ crystals [Ph.D. dissert.]. Univ. of Toronto.

Heider, F., Dunlop, D. J., and Sugiura, N., 1987. Magnetic properties of hydrothermally recrystallized magnetite crystals. Science, 236: $1287-1290$.

Karlin, R., and Levi, S., 1985. Geochemical and sedimentological control of the magnetic properties of hemipelagic sediments. $J$. Geophys. Res., 90:10373-10392.

Levi, S., and Merrill, R. T., 1978. Properties of single-domain, pseudo-single-domain, and multidomain magnetite. J. Geophys. Res., 83:309-323.

Lowrie, W., and Fuller, M., 1971. On the alternating field demagnetization characteristics of multidomain thermoremanent magnetization in magnetite. J. Geophys. Res., 76:6339-6349.

Petersen, N., and Vali, H., 1987. Observation of shrinkage cracks in ocean-floor titanomagnetites. Phys. Earth Planet. Inter., 46:197205. 
Petersen, N., von Dobeneck, T., and Vali, H., 1986. Fossil bacterial magnetite in deep-sea sediments from the South Atlantic Ocean. Nature, 320:611-615.

Sager, W. W., 1988. Paleomagnetism of Ocean Drilling Program Leg 101 Sediments: magnetostratigraphy, magnetic diagenesis, and paleolatitudes. In Austin, J. A., Jr., Schlager, W., et al., Proc. ODP, Sci. Results, 101: College Station, TX (Ocean Drilling Program), 327-360.

Schlich, R., Wise, S. W., Jr., et al., 1989. Proc. ODP, Init Repts., 120: College Station, TX (Ocean Drilling Program).

Schmidbauer, E., Mosheim, E., and Semioschkina, N., 1986. Magnetization and ${ }^{57} \mathrm{Fe}$ Mössbauer study of obsidians. Phys. Chem. Miner., 13:256-261.

Vali, H., von Dobeneck, T., Amarantidis, G., Förster, O., Morteani, G., Bachmann, L., and Petersen, N., 1989. Biogenic and lithogenic magnetic minerals in Atlantic and Pacific deep sea sediments and their paleomagnetic significance. Geol. Rundsch., 78:753-764.

Verosub, K. L., 1977. Depositional and postdepositional processes in the magnetization of sediments. Rev. Geophys. Space Phys., 15:129-143.

von Dobeneck, T., Petersen, N., and Vali, H., 1987. Bakterielle magnetofossilien. Geowiss. Zeit., 1:27-35.

Witte, W. K., and Kent, D. V., 1988. Revised magnetostratigraphies confirm low sedimentation rates in Arctic ocean cores. Quat. Res., 29:43-53.

Date of initial receipt: 2 January 1989 Date of acceptance: 14 September 1990 Ms 120B-128

Table 1. Low-temperature experiments on the sediment samples.

\begin{tabular}{lcc}
\hline $\begin{array}{l}\text { Core, section, } \\
\text { interval }(\mathrm{cm})\end{array}$ & $\begin{array}{c}\text { Decrease IRM } \\
(290 \mathrm{~K})(\%)\end{array}$ & $\begin{array}{c}\text { Increase IRM } \\
(77 \mathrm{~K})(\%)\end{array}$ \\
\hline $120-747 \mathrm{~A}-$ & & 65.0 \\
$3 \mathrm{H}-4,32$ & -13.0 & 15.0 \\
$6 \mathrm{H}-2,112$ & -8.5 & 70.0 \\
$9 \mathrm{H}-8,82$ & -6.7 & 33.0 \\
$14 \mathrm{H}-6,33$ & -8.0 & 25.0 \\
$16 \mathrm{H}-6,32$ & -4.0 & 14.0 \\
$18 \mathrm{X}-2,96$ & -10.0 & 29.0 \\
$26 \mathrm{X}-1,40$ & -60.0 & 28.0 \\
$120-751 \mathrm{~A}-$ & & 13.0 \\
$2 \mathrm{H}-2,50$ & -21.2 & -42.0 \\
3H-2, 120 & -34.0 & -33.0 \\
$14 \mathrm{H}-4,120$ & -5.0 & 0 \\
$15 \mathrm{H}-3,50$ & & \\
\hline
\end{tabular}




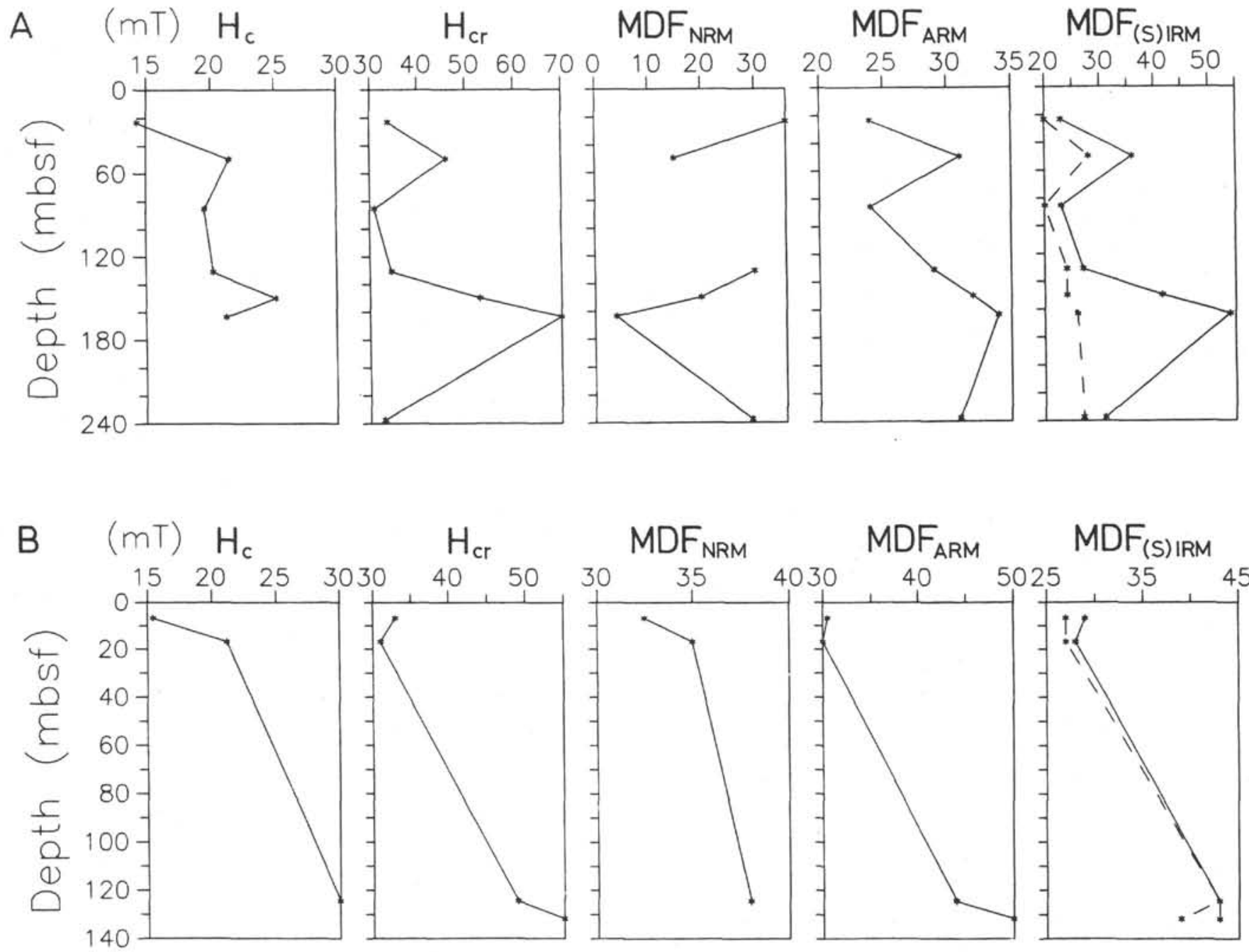

Figure 12. Downhole plots of coercive forces $\left(H_{c}\right.$ and $\left.H_{c r}\right)$ and median destructive fields of NRM, ARM, IRM, and saturation IRM. A. At Hole 747A there is little correlation between the MDF of NRM and the other magnetic parameters. There is a large gap between the MDFs of IRM $(100 \mathrm{mT})$ and SIRM for two samples that have a high coercivity phase. B. The four samples from Hole 751A fall into two groups with regard to their magnetic "hardness." 


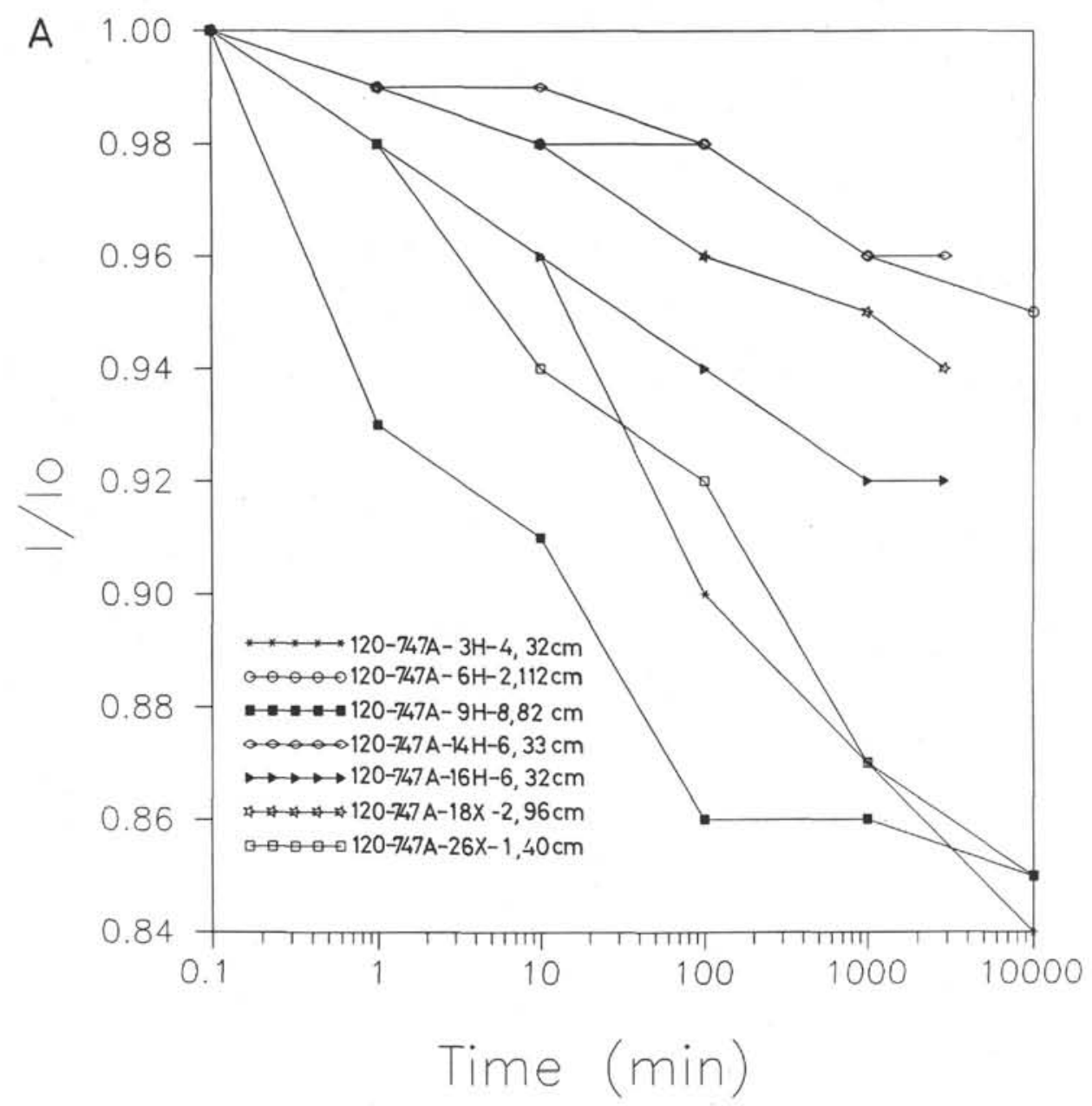

Figure 13. Semilogarithmic plot of saturation IRM vs. time. All samples showed viscous decay of their SIRMs. A. Three samples from Site 747 lost about $15 \%$ of the SIRM between $6 \mathrm{~s}$ and $10^{4} \mathrm{~min}$. B. The samples from Site 751 again form two groups in which the magnetically harder samples from Cores $120-751 \mathrm{~A}-14 \mathrm{H}$ and $-15 \mathrm{H}$ are a little more viscous than the samples with lower coercivity values from Cores $120-751 \mathrm{~A}-2 \mathrm{H}$ and $-3 \mathrm{H}$. 
F. HEIDER, B. LEITNER, H. INOKUCHI

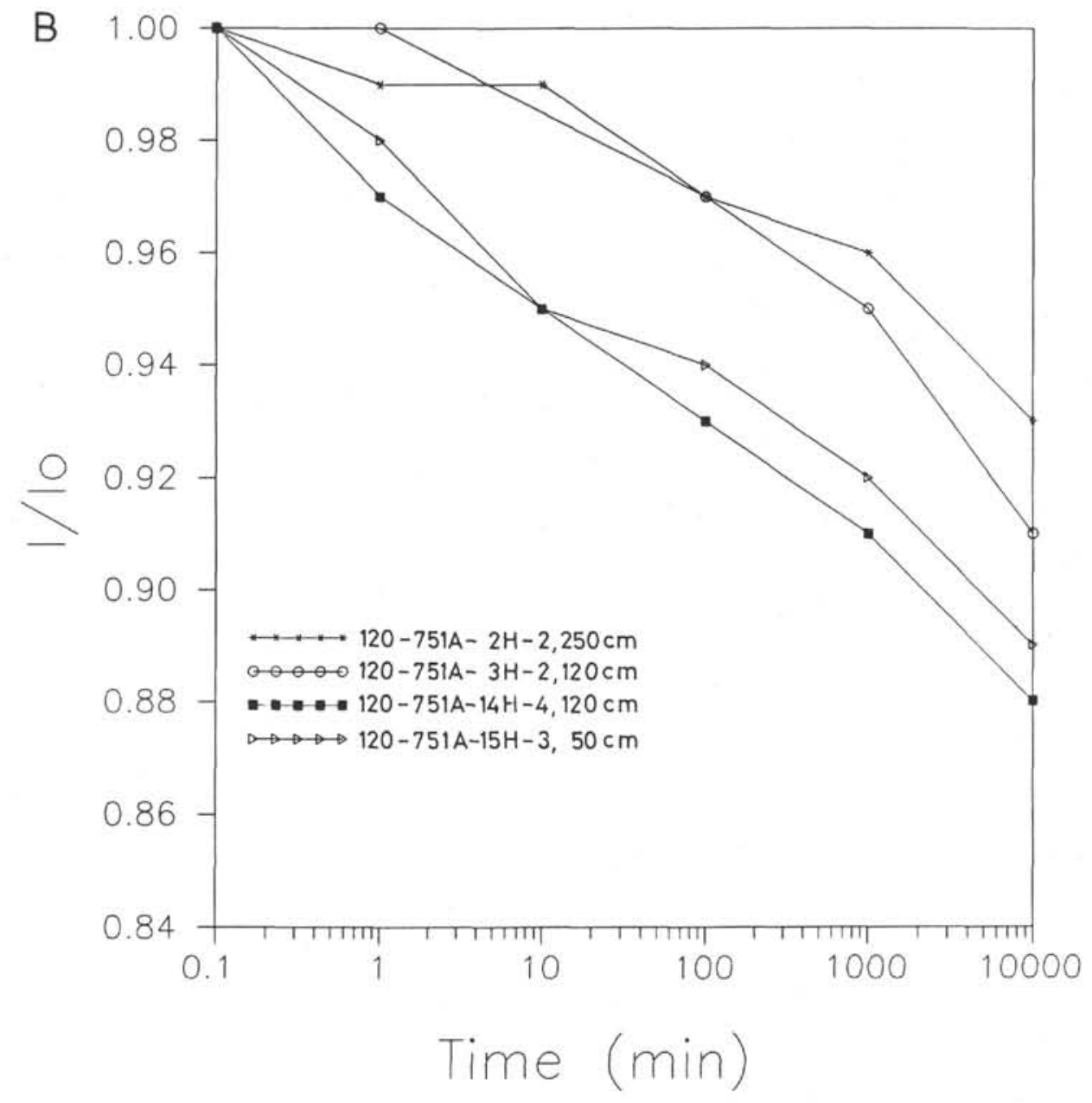

Figure 13 (continued). 
A

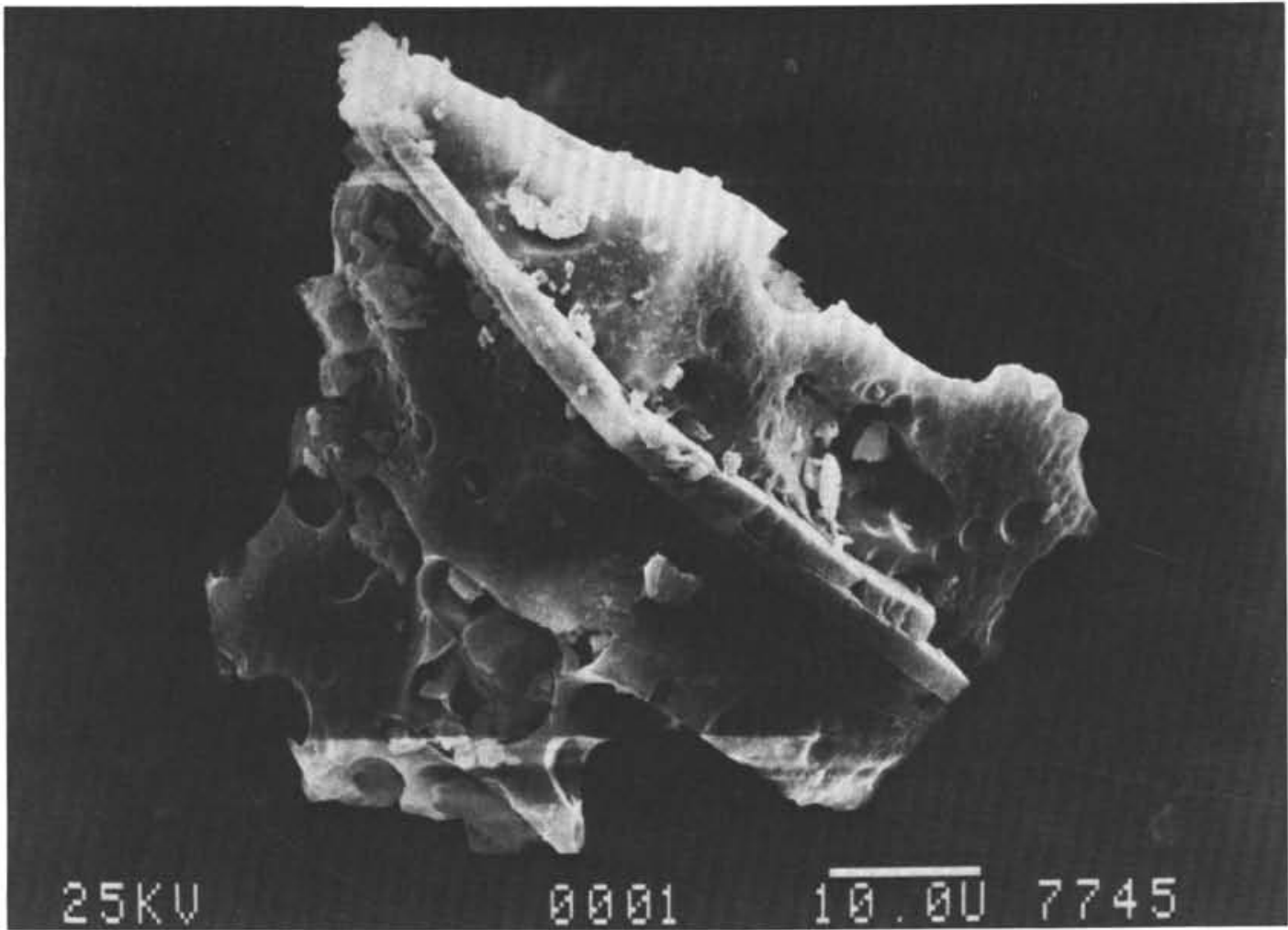

B

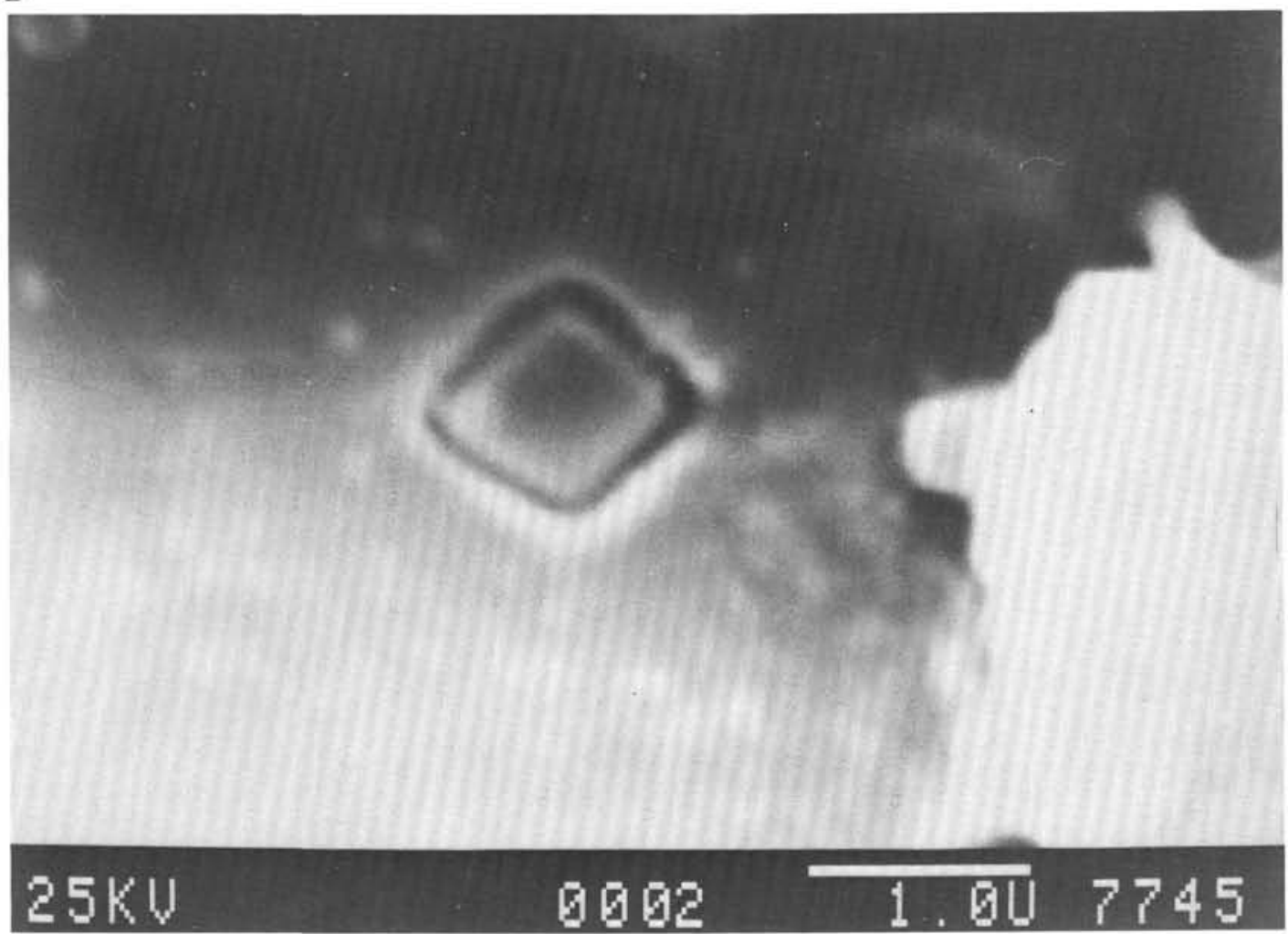

Figure 14. A. Scanning electron micrograph of volcanic glass particle. B. Enlargement of particle in Figure 14A showing small Fe-Ti oxide inclusion. 